\title{
Evidence of Standing Waves in Arc Jet Nozzle Flow
}

\author{
David M. Driver ${ }^{1}$, Joe Hartman ${ }^{2}$, Daniel Philippidis ${ }^{3}$, Eric Noyes ${ }^{4}$, Frank Hui ${ }^{5}$ and Imelda Terrazas-Salinas ${ }^{6}$ \\ NASA Ames Research Center, Moffett Field, California, 94035
}

\begin{abstract}
Waves spawned by the nozzle in the NASA Ames 60 MW Interaction Heating Facility arc jet were experimentally observed in pressure surveys at the exit of the nozzle. The waves have been seen in past CFD simulations, but were away from the region where models were tested (for the existing nozzles). However, a recent test series with a new nozzle extension $(229 \mathrm{~mm}$ exit diameter) revealed that these waves intersect the centerline of the jet in a region where it is desirable to put test articles, and that the waves may be contributing to non-uniform recession behavior seen in Teflon ${ }^{\mathrm{TM}}$ sublimation test articles tested in this new nozzle. It is reasonable to assume the ablation recession of thermal protection models will also be nonuniform due to exposure to these waves. This work shows that ablation response is sensitive to the location of test samples in the free jet relative to the location of the wave interaction, and that the issues with these waves can be avoided by choosing an optimum position for a test article in the free jet. This work describes the experimental observations along with the CFD simulations that have identified the waves emanating from the nozzle, as well as the instrumentation used to detect them. The work describes a recommended solution, derived by CFD analysis, which if implemented, should significantly reduce these flow disturbance and pressure anomalies in future nozzles.
\end{abstract}

\section{Nomenclature}

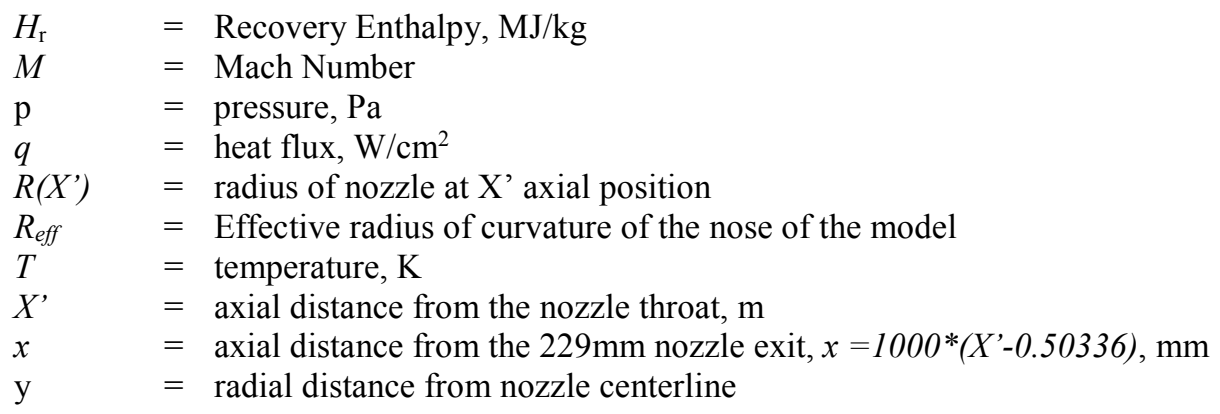

\section{Introduction}

rc jet flow characterization is part of an ongoing effort to improve arc jet testing and ana
Issues associated with arc jet testing are routinely being addressed as we become aware of
standing waves, generated by the nozzle throat section in the Ames arc jets had been previously
et.al. [1] in CFD simulations of both the Interaction Heating Facility (IHF) and Aerodynamic Heat
at NASA Ames. Subsequent simulations by the CFD community have attempted to include the
on the models being tested. For the existing set of conical nozzles, built decades ago, with exit
$330 \mathrm{~mm}, 546 \mathrm{~mm}, 762 \mathrm{~mm}$, and $1041 \mathrm{~mm}$, the effect of the waves on models was found to be
However, in the case of a new $229 \mathrm{~mm}$ ( 9 in.) exit diameter conical nozzle, specifically designed
it appears that these waves may be a problem for models being tested near the exit of this new

${ }^{1}$ Senior Research Scientist, Aerothermodynamics Branch, MS 230-2, Associate Fellow AIAA
${ }^{2}$ Senior Research Scientist, Sierra Lobo, MS 229-4
${ }^{3}$ Engineer, Aerospace Computing Inc., MS $229-4$
${ }^{4}$ Senior Research Engineer, Jacobs Technology, MS $229-4$
5 Test Engineer Thermophysics Facilities Branch, MS 242-2
${ }^{6}$ Test Engineer Thermophysics Facilities Branch, MS $242-2$

American Institute of Aeronautics and Astronautics 
nozzles use the same $60.3 \mathrm{~mm}$ diameter throat section but only this intermediate size nozzle involves placing the models in the vicinity of where the waves are predicted to intersect the centerline of the free jet.

Waves in supersonic nozzles are commonplace and can be generated by roughness, subtle discontinuities in geometry, and non-optimal nozzle shapes. Minimizing waves requires careful attention to details of the design and manufacturing. Designing contoured nozzles typically involves using method of characteristics or adjoint methods of optimization. The Ames arc jets use conical nozzles to simplify design and installation. Conical nozzles are so simple (straight wall section) that very little attention is paid to the nozzle throat design. In the case of conical nozzles the typical strategy is to use a circular arc at the throat which abruptly transitions to a straight conical section such that the tangency angle is matched. Unfortunately, this strategy (adopted in the 1960s) provides a mechanism for creating waves, and this is apparent in CFD performed by Prabhu et.al. [1]. The mechanism causing waves can be most easily seen when writing the momentum equations in a streamline aligned coordinate system. Here the local normal

momentum equation becomes $\rho \frac{V_{s}^{2}}{R_{S}}=\partial \mathrm{p} / \partial \eta$, where $V_{s}$ is the streamwise component of velocity, $R_{s}$ is the radius of curvature of the streamline, $\eta$ is the direction normal to the streamline which points in the $R_{S}$ direction. The equation shows that an abrupt change in curvature $\left(1 / R_{s}\right)$ will cause a jump in pressure and consequently a wave. With the advent of sophisticated instrumentation, it is possible to experimentally see evidence of these waves.

Flow quality in arc jets is often quantified by "burn" patterns on test articles made of polytetrafluoroethylene (PTFE) commonly known as Teflon ${ }^{\mathrm{TM}}$ (developed by DuPont in 1938, acquired by Chemours). The PTFE material ablates (sublimates) more or less proportional to heating rate. The recession of PTFE samples gives a global map of the heating distribution on a test article. PTFE Teflon is chosen for its low sublimation temperature $\left(<1000^{\circ} \mathrm{C}\right)$, high heat of vaporization and low thermal conductivity, and has been in use since the 1960's to characterize arc jet flows. PTFE Teflon is sensitive to variations in convective heat flux and can provide a measure of non-uniformities in heat flux on a test article. Cold wall heating rate, $\mathrm{q}_{\mathrm{cw}}\left(\mathrm{W} / \mathrm{cm}^{2}\right)$, correlates [2] with the recession rate, $\dot{s}(\mathrm{~cm} / \mathrm{s})$, of PTFE Teflon according to $\mathrm{q}_{\mathrm{cw}}=\dot{s} * 2150 *\left(2.2+\Lambda *\left(\mathrm{H}_{\mathrm{r}}-2.2\right)\right) *\left(\mathrm{H}_{\mathrm{r}} /\left(\mathrm{H}_{\mathrm{r}}-2.2\right)\right)$, where $\mathrm{H}_{\mathrm{r}}$ is recovery enthalpy $(\mathrm{MJ} / \mathrm{kg})$ and $\Lambda=0.44$ is a blowing correction for laminar flow.

Additional flow quality checks are performed with fast response instruments which can measure stagnation heating and pressure as they are rapidly swept through the free jet of the arc heated flow. The radial distributions of heating and pressure are useful in identifying radial variations in enthalpy, and more recently, the existence of standing waves in the free stream.

This paper describes the effort to characterize a new $229 \mathrm{~mm}$ (9 in.) nozzle using fast response instrumentation to measure heat flux and pressure as a function of radial distance from the nozzle centerline. CFD is performed to corroborate the experimental results and to provide insight into what is necessary to eliminate these waves in future nozzle designs.

\section{Arc Jet Description}

The IHF has been in operation for over four decades and provides a high enthalpy supersonic plasma flow stream to simulate aerodynamic heating on high-speed vehicles for long durations [3]. NASA has developed a family of conical nozzles used to test stagnation material samples. Separate conical segments with identical expansion angle are attached, one after another, to increase the nozzle expansion ratio. This creates joints between adjacent segments. Many customers have been asking for an intermediate nozzle size between the existing $152 \mathrm{~mm}(6 \mathrm{in}$.) and $330 \mathrm{~mm}(13$ in.) nozzles. One previous attempt at designing and building an intermediate size nozzle, $203 \mathrm{~mm}$ ( 8 in.) exit diameter, was executed in 2007 [4] and was met with mixed results. Flow quality was assessed with recession patterns on $101.6 \mathrm{~mm}$ (4 in.) Teflon stagnation test articles - and the resulting Teflon ablation patterns were significantly nonuniform and asymmetric. At the time the poor performance was attributed to a design feature that was unique to this nozzle; the nozzle was designed with a significant cavity and step at the joint between the $152 \mathrm{~mm}$ exit diameter throat section and the $203 \mathrm{~mm}$ conical extension segment. NASA had insufficient instrumentation at the time to diagnose the problem (such as radial surveys of the flow). Due to the poor performance on Teflon, the $203 \mathrm{~mm}$ nozzle extension has not been used since.

More recently a $229 \mathrm{~mm}$ (9 in.) nozzle was designed and built for the IHF $60 \mathrm{MW}$ facility (see Fig. 1). The nozzle is an extension of the existing nozzle throat section (152mm exit diameter). The extension is a smooth continuation of the $10^{\circ}$ conical shape. There is no cavity or gap built into the joint. 

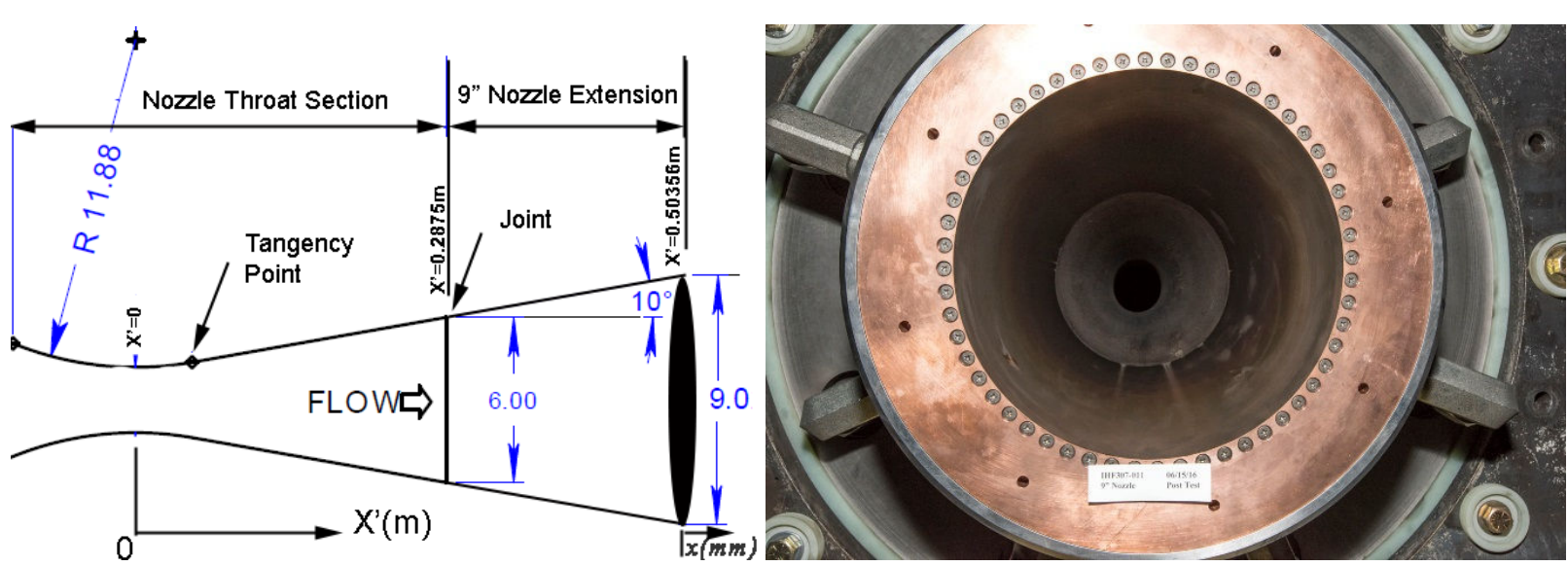

Figure 1. IHF throat and $229 \mathrm{~mm}(9$ in.) nozzle extension a) sketch b) photo after 10 runs (view of exit)

The cone angle of the nozzle extension was designed to match the cone angle of the nozzle throat segment to better than $0.03^{\circ}$. The joint between the existing throat section and the new nozzle extension is relatively step free, with an as built entrance diameter that matches the nozzle throat section exit diameter to within a $0.05 \mathrm{~mm}(0.002 \mathrm{in}$.) The largest step is a forward facing step approximately $0.05 \mathrm{~mm}$ in size at the 6 o'clock position; tan streaks can be seen at the 6 o'clock position in Fig $1 \mathrm{~b}$ and the upstream end of the streak coincides with the location of the steps. Figure 2a shows a straight edge against the nozzle at the location of the joint and shows light between the straight edge and the nozzle joint being relatively minimal (albeit only $0.05 \mathrm{~mm}$ ). Figure $2 \mathrm{~b}$ shows the degree to which the as built wall shape deviates from the design, which had been considered satisfactory.
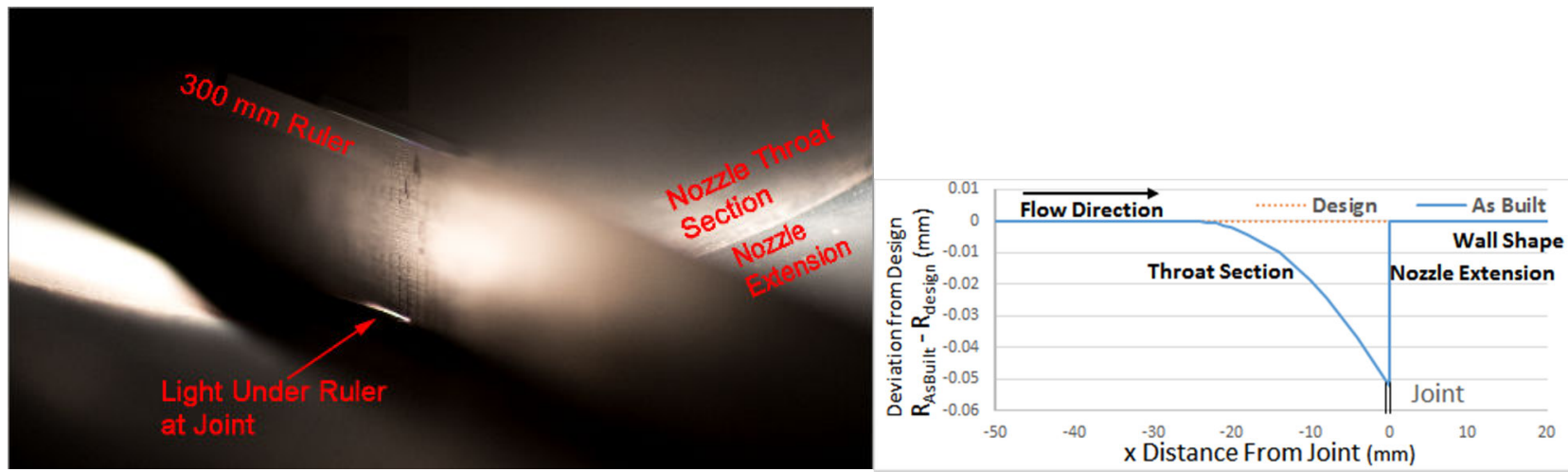

a) close-up of the joint region

b) As built wall geometry (deviation from design)

Figure 2. Joint between the IHF nozzle throat section and the $229 \mathrm{~mm}(9$ in.) nozzle extension

The new $229 \mathrm{~mm}(9 \mathrm{in}$.) nozzle was evaluated with Teflon test articles, as well as pressure and heat flux probes (that were swept through the flow).

\section{Instrumentation}

After the experience with the $203 \mathrm{~mm}$ ( 8 in.) nozzle, it was decided that the checkout tests for the new $229 \mathrm{~mm}(9$ in.) nozzle would include a much more comprehensive set of measurements, and to confirm observations with more than one type of measurement device.

\section{A. Stagnation Heat Flux and Pressure Probes}

The test chamber of the IHF is fitted with a three sting arm model insertion system that swings each model along a 1.3 to $1.5 \mathrm{~m}$ radius arc through the centerline of the free-jet. The probe or test article may be located at a specified axial distance from the exit plane of the nozzle. The East and West sting arms are ideally suited to performing radial traverses of the flow. The high-performance model insertion system allows customers to use uncooled fast response instrumentation that can be rapidly swept through the flow [5]. Two such examples are shown in Figures 3 and 4. Figure 3 shows a $12.7 \mathrm{~mm}$ diameter Sphere Cone probe with Coaxial thermocouple (TC) sensor at its center (aka 
$13 \mathrm{~mm}$ Sphere Cone probe). The probe was developed and built by Arnold Engineering Development Center (AEDC) [6] in Tullahoma Tennessee; it uses a Coaxial TC sensor built by Medtherm Inc [7].

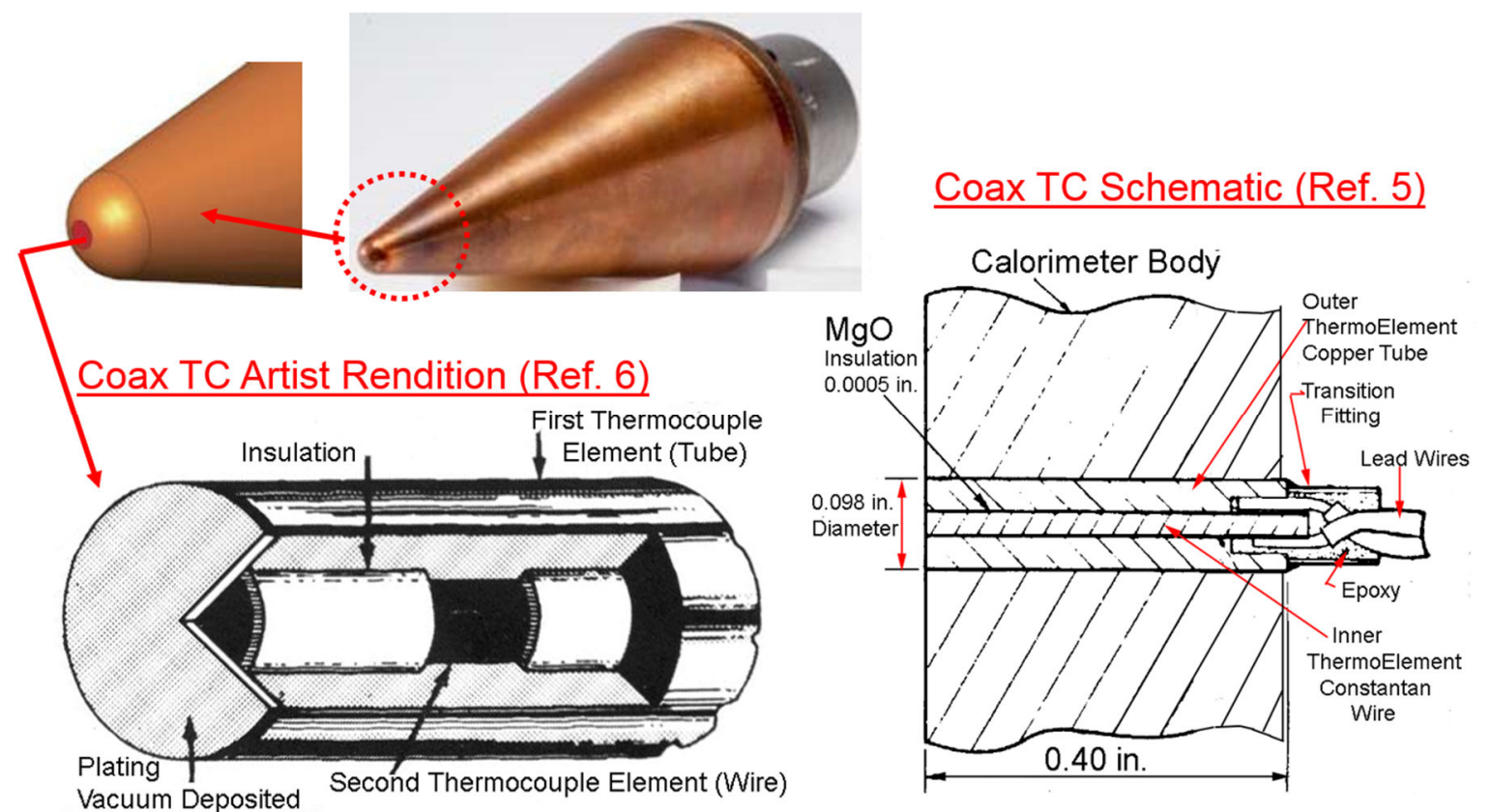

Figure 3. 12.7mm Sphere-Cone Probe with Coaxial TC mounted in the tip of the probe.

Figure 4 shows a $101.6 \mathrm{~mm}$ diameter Hemispherical Null Point calorimeter probe, built in-house at NASA Ames using a $12.7 \mathrm{~mm}$ long Null Point built by Medtherm Corporation. It contains a pitot pressure port near the stagnation point connected to a high-speed transducer that is housed inside the probe body.

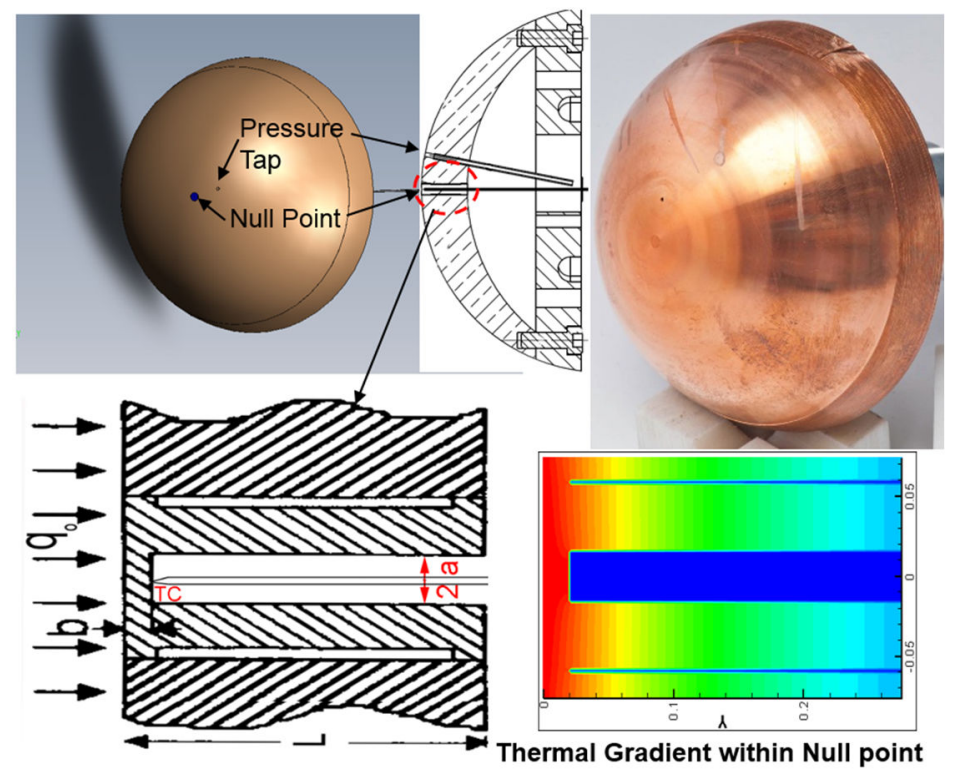

Figure 4. 101.6mm diameter hemispherical probe with Null Point and pressure tap.

Both sensor types (Coaxial TC and Null Point) rely on a thermal transient response analysis [8] to deduce the heat transfer rate to the sensor's surface using the measured temperature rise of the thermocouple at (or near) the front surface of the sensor (while it sweeps across the flow stream). Figure 5 shows an example of the heating and pressure distribution obtained by the $101.6 \mathrm{~mm}$ diam. Hemi-spherical probe with Null Point as it is traversed across the free jet 
of the $229 \mathrm{~mm}$ ( $9 \mathrm{in}$.) nozzle of the IHF. The probe was swept through the flow at $76 \mathrm{~cm} / \mathrm{sec}$ at condition $\mathrm{c} 4$ (described later) while measuring heat flux and pressure.

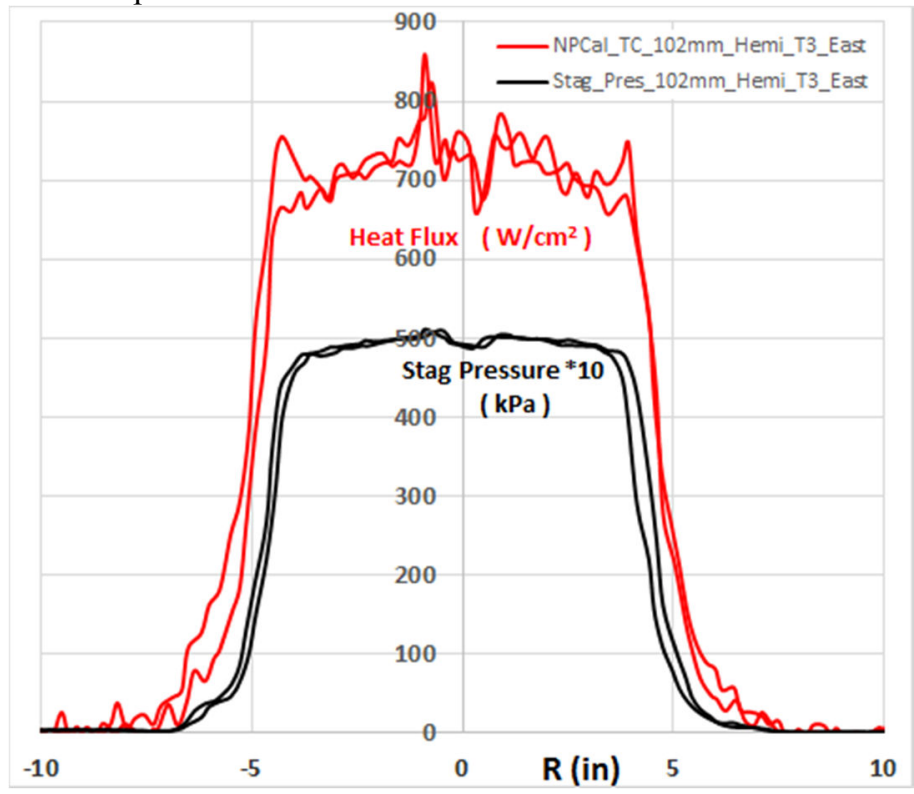

Figure 5. IHF 229mm Nozzle Radial Surveys (measured by 101.6mm diam. Hemispherical Null Point Probe) at condition MSL-c4 at the $x=76 \mathrm{~mm}$ station downstream of the nozzle exit.

The figure shows data from the probe for both forward and backward sweeps through the flow as indicated by two red lines for heating and two black lines for pressure. A small local minimum in pressure near the centerline of the jet can be seen in the radial distribution of pressure (this will be discussed later). There are also local maximums and minimums in heating near the centerline of the flow.

The local minimum in pressure does not appear to be an artifact of the relatively large $101.6 \mathrm{~mm}$ hemispherical probe as evidenced by the good agreement with a smaller $9 \mathrm{~mm}$ diam. sphere cone stagnation pressure probe (see Fig. 6) at a somewhat lower condition. The $9 \mathrm{~mm}$ diam. SphereCone pitot pressure probe is similar to the $12.7 \mathrm{~mm}$ diam. SphereCone probe except that its nose radius is $30 \%$ smaller and it has a pressure tap hole and transducer at its center rather than a heat flux sensor.

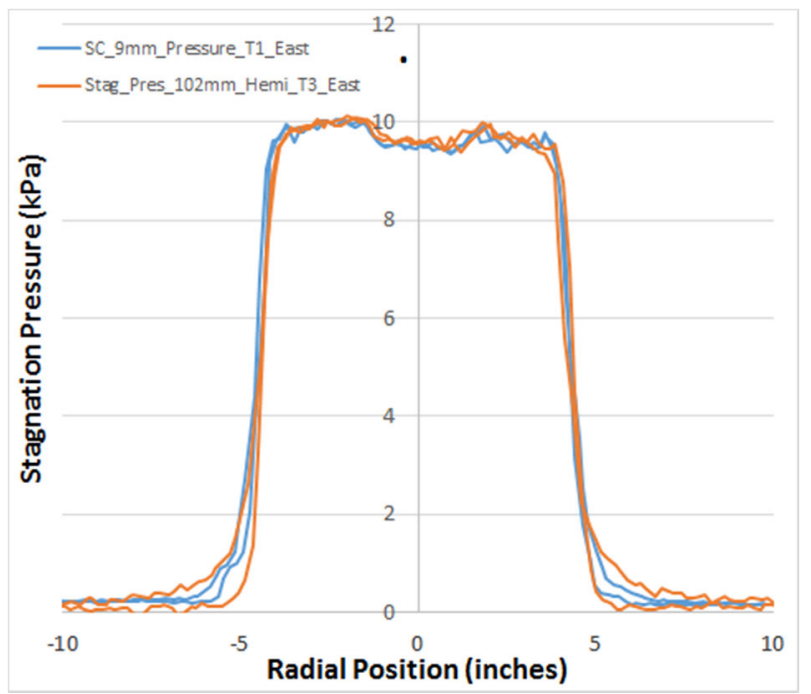

Figure 6. Radial distributions of stagnation pressure measured by the $9 \mathrm{~mm}$ diam. SphereCone and 101.6mm diam. Hemi probes at the same arc-heater reservoir condition.

In the interest of performing comparisons of different sensor types, a similar $101.6 \mathrm{~mm}$ diameter hemispherical probe was built with a Coaxial TC sensor installed at the tip of the probe (instead of a Null Point sensor). Likewise a 
$12.7 \mathrm{~mm}$ diameter sphere cone probe was built with a Null Point at its center (instead of a Coaxial TC). Existing $101 \mathrm{~mm}$ diam. hemispherical probes containing two different sensors, Slug-type [9] and Gardon-type [10] are compared with the null-point data. In the interest of obtaining redundant measurements with different body types and sensor types a large number of stagnation probes were tested during various runs in the test campaign, the probes tested included (dimensions are the probe diam.):

- $\quad$ 101.6mm (4 in.) Hemispherical Null Point

- $\quad 101.6 \mathrm{~mm}$ (4 in.) Hemispherical Gardon Gage

- $\quad 101.6 \mathrm{~mm}$ (4 in.) Hemispherical Coax TC

(shown on far left of Fig. 7 and Fig. 4)

- $\quad 101.6 \mathrm{~mm}$ (4 in.) Hemispherical slug calorimeter

- $\quad 101.6 \mathrm{~mm}$ (4 in.) IsoQ Null Point

- $\quad 12.7 \mathrm{~mm}$ SphereCone Coax TC

- $\quad 12.7 \mathrm{~mm}$ SphereCone Null Point

(shown in center of Fig. 7 and middle of Fig. 9b)

(shown on far right of Fig. 7)

(shown in Fig. 9c)

(shown in middle of Fig. 10 and Fig. 3)

- $9 \mathrm{~mm}$ SphereCone pitot pressure probe

The East sting arm was configured with three fast response calorimeters, one on each prong of a three pronged model holder referred to as a Trident (See Fig. 7). In this case each probe is a $101.6 \mathrm{~mm}$ (4 in.) diameter hemispherical shape with a Null Point sensor in the far left probe, a Gardon gage sensor in the middle probe and a Coaxial TC sensor in the far right probe. Mounting three probes on the same sting arm allows each probe to follow the same trajectory through the flow within milliseconds of each other, helping to eliminate the variation in heating due to different sweep trajectories. Note the East and West sting arms follow different trajectories through the flow; the East sting arm traverses from bottom east to upper west while the West sting arm traverses from the bottom west to the upper east these two trajectories are nearly orthogonal to each other. Using the trident makes it is easier to make a one to one comparison between different probes.

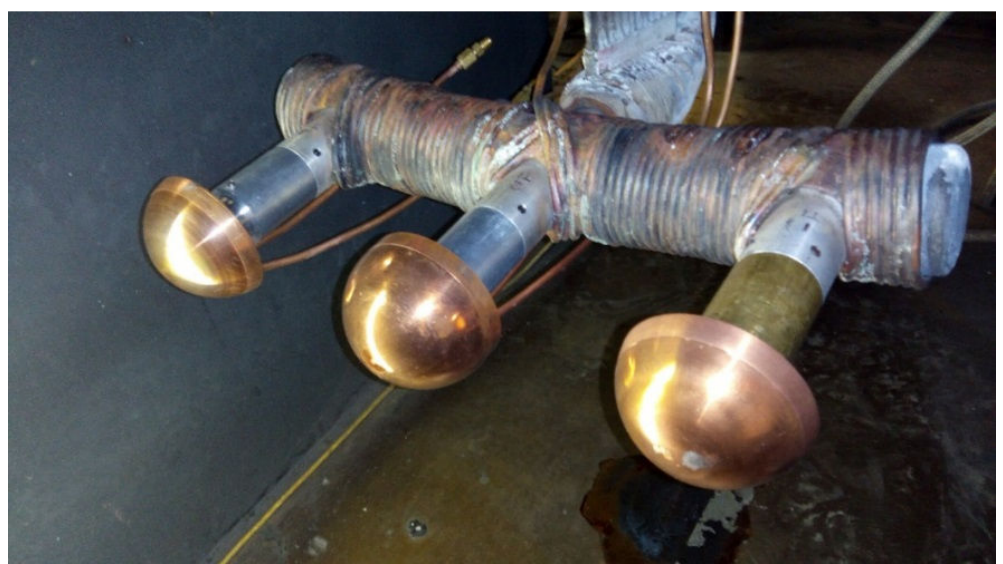

Figure 7. 101.6mm Hemispherical calorimeters installed on a Trident mounted on the East Sting Arm

Figure 8 shows the heat flux measured by each of the probes shown in Fig. 7; measurements were made at the MSL-c4 condition (see Table 1) at a location $x=76 \mathrm{~mm}$ ( $3 \mathrm{in}$.) downstream of the $229 \mathrm{~mm}$ diam. nozzle exit. Both forward and backward sweeps are shown for each probe (two lines for each color), and the difference between heat transfer measured on the forward and backward sweeps is relatively minimal (an indication of good repeatability and independence from direction being swept).

The shape of the radial distribution of heat flux is similar for each of the sensors (Coaxial TC sensor, the Null Point sensor and the Gardon Gage sensor). This provides confidence that local minimums and maximums seen in the heating distribution (near centerline) are real and not just an artifact of any one particular sensor.

A thermal-capacitance calorimeter, or slug, (Figure 9c), was inserted onto centerline to measure heat flux. This uncooled sensor must dwell stationary for a short period of time $(<2 \mathrm{sec})$ in order to measure transient temperature rise of a known quantity of material, usually copper, while exposed to a constant surface heat flux. This gives an alternate method of comparing heat flux at one point, the centerline, with measurements obtained by the fast-sweeping probes. 


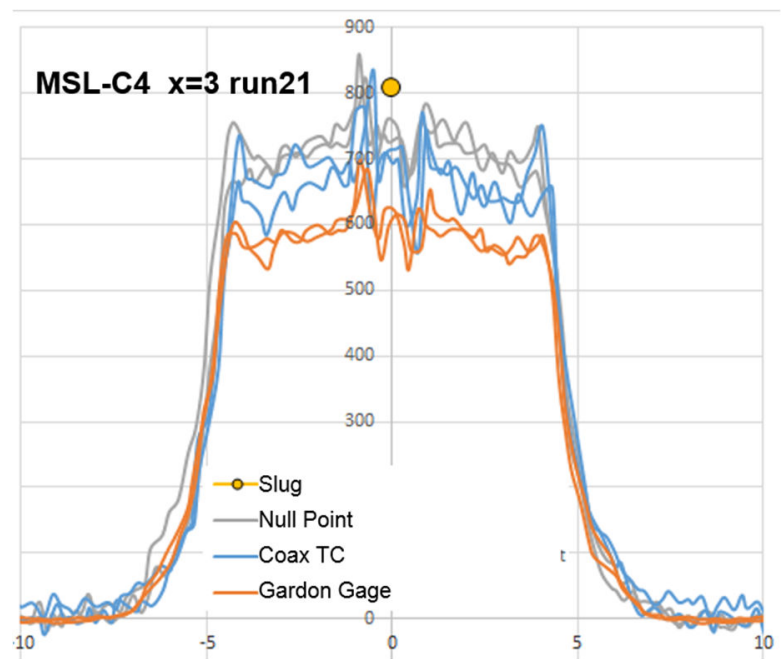

Figure 8. Comparison of heat flux measurements by various sensors in $101.6 \mathrm{~mm}$ (4 in.) diam. Hemispherical probes

Nevertheless there are differences in the absolute magnitude of heat flux measured by each of the different sensors:

- Coax TC

- Null Point measures

- Gardon Gage measures

- $\quad$ Slug measures used as the baseline for comparison

$+7 \%$ higher than the Coax TC

$-13 \%$ lower than the Coax TC

$+15 \%$ higher than the Coax TC

The leading theories to explain the difference include:

1) The Null Point (Fig. 9a) is missing material at its center (and periphery) causing the temperature to rise faster than would the temperature of a solid sensor - notice the difference in temperature between sensor and the calorimeter body in a $2 d$ simulation of a Null Point (Fig. 9a).

2) Some of the Gardon gages (Fig. 9b) come with a dimple in the middle (probably associated with the spot welding process). One might think that the calibration would take care of any effects due to a dimple. However calibrations are done with a radiant heating facility while heating in the arc jet is convective, for which the effect of the dimple is different. Aerodynamic heating on the dimpled Constantan foil was found to be $7 \%$ less than that of a flat foil (according to CFD). Also, a Gardon gage is only as good as its calibration; the gages are typically calibrated at low heat fluxes and the calibration is extrapolated to high heat fluxes assuming linearity of the response.

3) The slug calorimeter (Fig. 9c) is isolated from the calorimeter body by a gap, which may be permitting a small amount of plasma flow and heating along the side of the slug (especially if the flow is stagnating on the gap rather than the center of the slug). Any augmentation to the slug's heating due to flow along its side wall is not accounted for in the analysis.

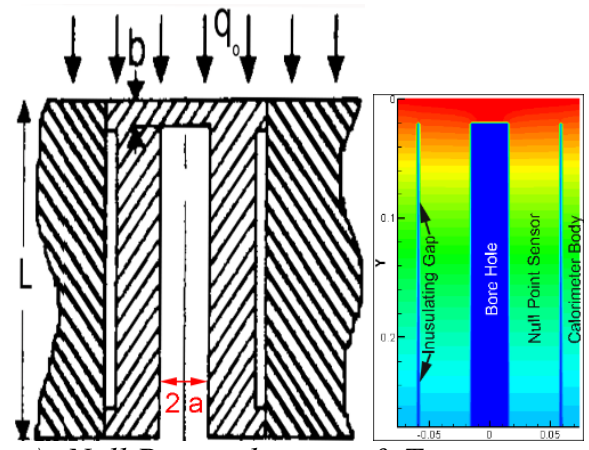

a) Null Point schematic \& Temperature

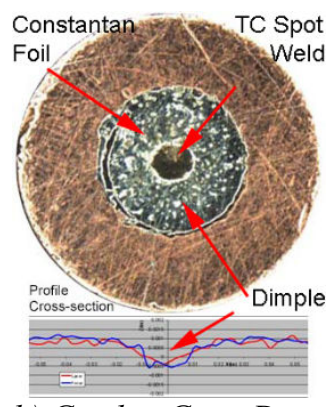

b) Gardon Gage Dimple \& Temperature

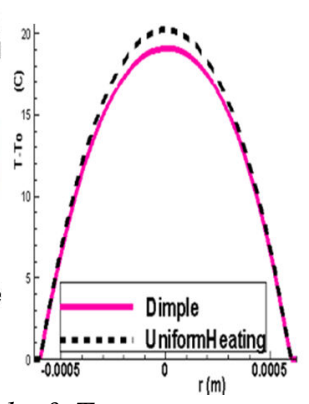

Figure 9. Various heat flux sensors and their imperfections

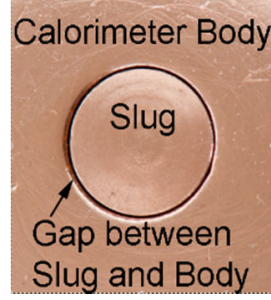

c) Slug gap 
We also ran probes of different shapes and sizes on the Trident (see Fig. 10). Occasionally, in prior test series, we would see differences in heating between large and small probes that could not be explained by nose radius effects. It may be the case that waves in the nozzle are interacting differently with probes of different shape and size.

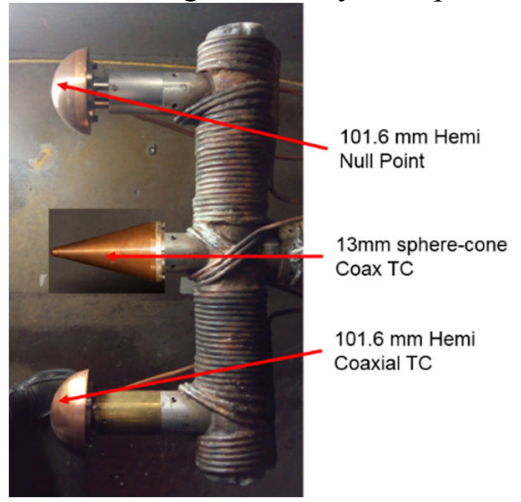

Figure 10. Various different types of calorimeters installed on a Trident mounted on the East Sting Arm

Figure 11 shows an example of the heat flux measured by two Coax TC probes shown in Fig. 10; one being the $12.7 \mathrm{~mm}$ SphereCone and the other being the $101.6 \mathrm{~mm}$ Hemispherical probe. The measurements were obtained at MSL-c4 condition with the probes at a location $x=76 \mathrm{~mm}$ downstream of the $229 \mathrm{~mm}$ diam. nozzle exit. The heat flux measured by the $12.7 \mathrm{~mm}$ SphereCone Coaxial TC probe is multiplied by $\operatorname{sqrt}\left(\mathrm{R}_{\mathrm{eff}} / 50.8 \mathrm{~mm}\right)$ to account for the effect of radius on the heat flux, where $\mathrm{R}_{\text {eff }}$ is estimated to be $9 \mathrm{~mm}$ to account for the flat face on the tip of the otherwise $6.35 \mathrm{~mm}$ radius probe (the sensor at the tip is flat). Local peaks and valleys in the radial heating distribution (near centerline) can be seen in the measurements made by the $101.6 \mathrm{~mm}$ probe, these are repeatable and seen by other $101.6 \mathrm{~mm}$ hemispherical probes (recall Fig. 8). The smaller $12.7 \mathrm{~mm}$ SphereCone probe does not experience these variations in heating with radial position. The differences in the behavior of the two probes is likely due to a difference in the interaction between the probe and the waves (which will be discussed later).

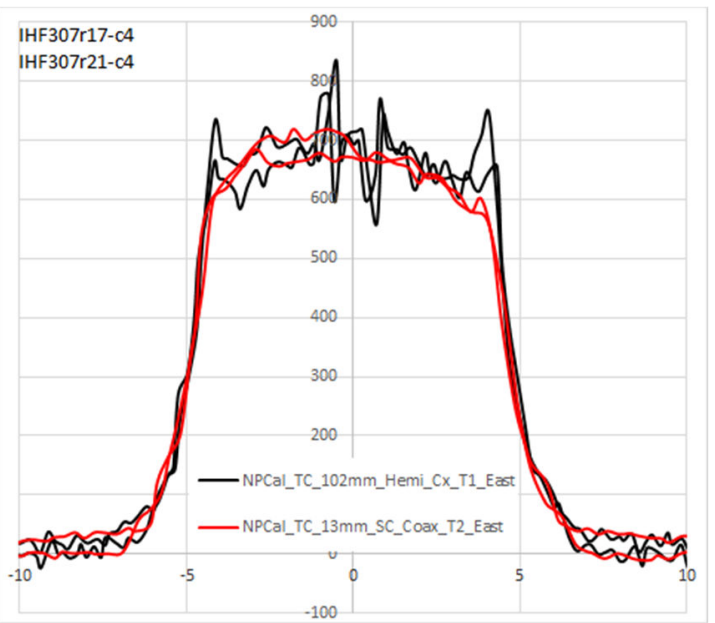

Figure 11. Heat flux measured by different size probes at condition $\mathrm{c} 4$ at $\mathrm{x}=\mathbf{7 6} \mathrm{mm}$

These local extremes near the centerline are repeatable and are common at other test conditions when the $101.6 \mathrm{~mm}$ hemispherical shaped probe is used (see Fig. 12a \& 12b). The Gardon gage probe is used to illustrate this point, as the signal is less noisy than that of the Null Point probe (albeit measuring slightly lower heating).

To summarize, it would appear that probes with different heat flux sensor types give similar radial distributions of heating for a given size probe. However larger size probes may be more effected by the waves than are smaller probes. Measurement of stagnation pressure may be less sensitive to the size of the probe, and there appears to be a local minimum in the radial distribution of pressure for surveys ahead of the $\mathrm{x}=127 \mathrm{~mm}$ station. It is reassuring to see that more than one type of sensor gives the same result. 

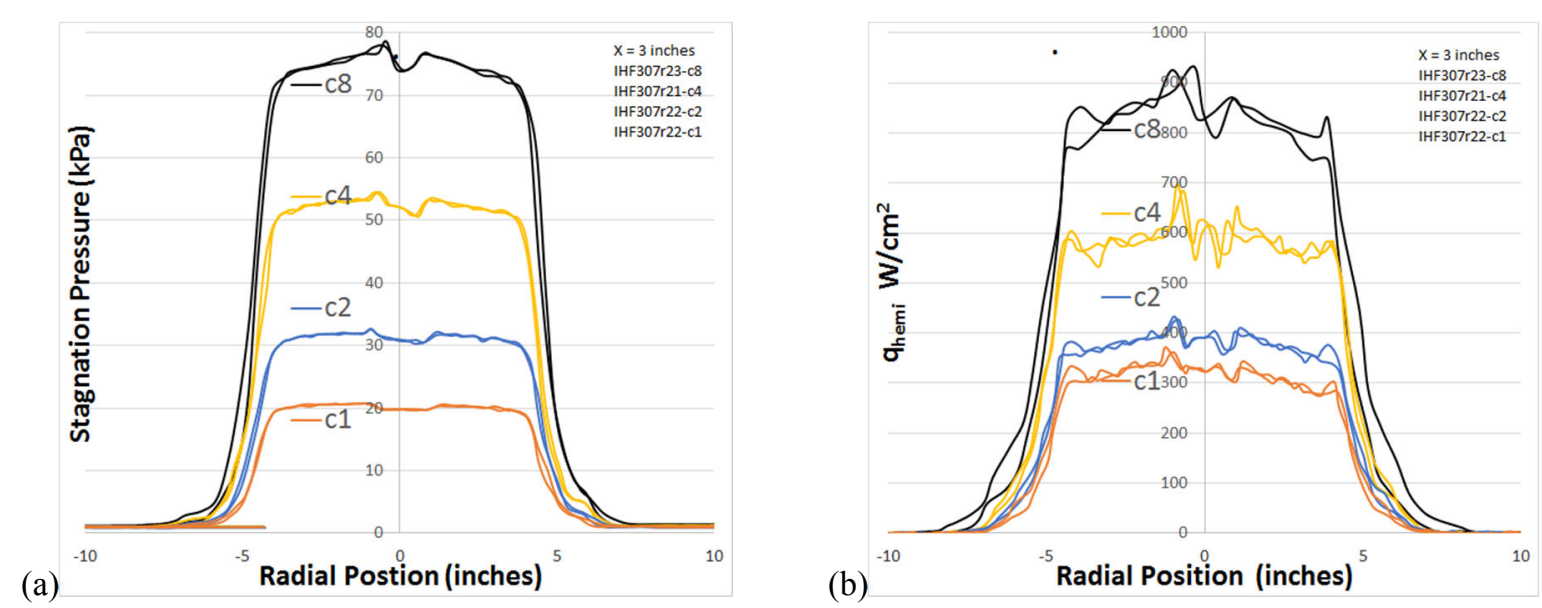

Figure 12. Radial distributions of stagnation pressure and heating (measured by $101.6 \mathrm{~mm}$ Hemispherical Gardon Gage probe) at $\mathbf{x}=\mathbf{7 6} \mathrm{mm}$ for various arc heater conditions.

\section{B. PTFE Teflon Test Articles}

A Teflon stagnation article dwells on the centerline of the free jet for a period of a few seconds (10-30s) during which time the surface ablates (via sublimation) and recedes on the order of several millimeters. The uniformity of the recession can be an indicator of the uniformity of heating of the model, therefore the spatial uniformity of the enthalpy and pressure in free stream flow. Teflon recession is thought to be a good qualitative indicator of heat flux distribution on the face of the probe. Teflon test articles were machined in the shape of either a $101.6 \mathrm{~mm}(4$ in.diameter) IsoQ or a $101.6 \mathrm{~mm}$ (4 in.diameter) flat face (see Fig. 13). IsoQ refers to a cylinder whose front face is machined with a nose radius that is equal to the diameter of the cylindrical cross-section. The shoulder radius of the IsoQ was $6.35 \mathrm{~mm}(0.25 \mathrm{in}$.) and the Flat Face models was $9.5 \mathrm{~mm}(0.375 \mathrm{in}$.). The IsoQ shape is desirable because the shape produces a relatively uniform heating across its face, resulting in relatively uniform recession during ablation.
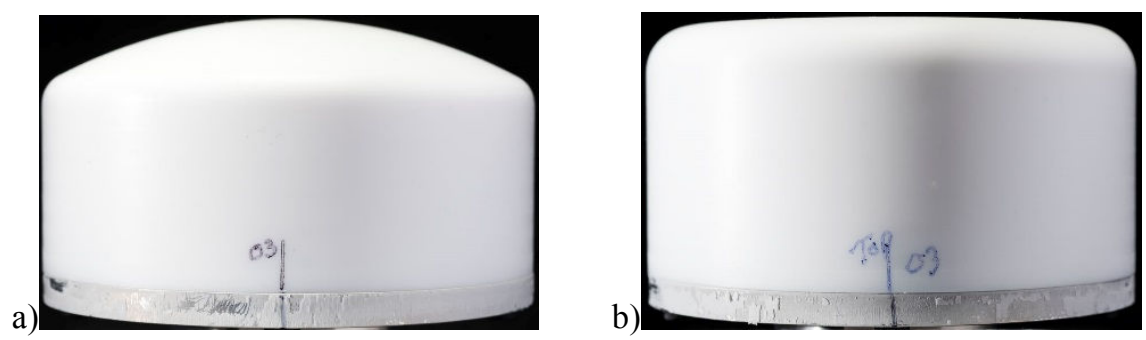

Figure 13. Teflon Test Articles 101.6mm (4 in.) diameter a) IsoQ and b) Flat Face

The majority of tests were performed with the $101.6 \mathrm{~mm}(4 \mathrm{in}$.) IsoQ, but as the IsoQ test articles were depleted we began using $101.6 \mathrm{~mm}$ (4 in.) flat faced test articles. The post-test distribution of recession was measured for each Teflon sample to assess the flow quality and suitability of a given condition for testing thermal protection system (TPS) materials. Typically Teflon shows anomalous flow behavior much more readily than do test articles made of higher heat flux capable materials used in TPS. Consequently if Teflon recession looks uniform across the face of the test article, then it is relatively safe to say that the ablator test article will experience uniform heating.

\section{Test Results}

Tests of the IHF $229 \mathrm{~mm}$ ( 9 in.) exit diam. nozzle were performed at a number of arc heater conditions which spanned the operating envelop of the facility (see Table 1). The description of the Test Case (column 1), includes the name of the program associated with the condition of interest, i.e., MSL refers to Mars Science Laboratory program and CEV refers to the Crew Exploration Vehicle program (aka Orion). The suffix in the Test Case description contains either the letter "a" or "c" to represent a case in which add-air is injected vs. a case with minimal add-air (respectively). "Add-air" refers to a flow of room-temperature air into the arc column after the last electrode but before the aerodynamic throat of the nozzle in order to reduce the bulk enthalpy of the arc-heated flow and therefore reduce the heating rate to a test article while maintaining a desired stagnation pressure. The suffix contains a number that has no particular meaning, except in the case of MSL in which the larger the number the more severe the condition. Other 
conditions were tested but not reported. The stagnation model conditions in Table 1 ( $\mathrm{P}_{\text {stag }}$ and $\mathrm{q}_{4}$ "Hemi $)$ are typically used in subsequent material response modeling. $\mathrm{H}_{\text {sonic }}$ is the estimated bulk flow enthalpy.

Table 1. Test Conditions

Test

Case amps

MSL-c1 2000

MSL-c4 3500

MSL-c8 6000

MSL-a1 3500

CEV-a13 3450

$\begin{array}{lll}\text { Volts } & \text { Main Air } & \text { Add Air } \\ \text { Volts } & \text { gm/s } & \text { gm/s } \\ 3430 & 200 & 55 \\ 5910 & 546 & 55 \\ 6600 & 741 & 55 \\ 4795 & 330 & 551 \\ 2720 & 105 & 645\end{array}$

\begin{tabular}{|c|c|c|c|c|}
\hline \multirow{3}{*}{$\begin{array}{l}\text { Argon } \\
\mathrm{gm} / \mathrm{s}\end{array}$} & \multicolumn{4}{|c|}{ probe at $x=76 \mathrm{~mm}$} \\
\hline & $\mathrm{P}_{\text {plenum }}$ & $\mathrm{P}_{\text {stag }}$ & $\mathrm{q}_{4 " \mathrm{Hemi}}$ & $\mathrm{H}_{\text {sonic }}$ \\
\hline & $\mathrm{kPa}$ & $\mathrm{kPa}$ & $\mathrm{W} / \mathrm{cm} 2$ & $\mathrm{MJ} / \mathrm{kg}$ \\
\hline 21 & 180 & 19.8 & 375 & 7.8 \\
\hline 42 & 555 & 52.0 & 706 & 15.6 \\
\hline 54 & 810 & 75.9 & 995 & 24.4 \\
\hline 59 & 593 & 52.3 & 350 & 7.2 \\
\hline 51 & 350 & 30.7 & 92 & 2.9 \\
\hline
\end{tabular}

\section{A. $229 \mathrm{~mm}$ Nozzle Characterization using Teflon}

Teflon was exposed to each of the conditions listed in Table 1. Figure 14 shows the post-test shape of Teflon test articles that were tested at a location $x=76 \mathrm{~mm}$ ( $3 \mathrm{in}$.) downstream of the nozzle exit. The IsoQ shape is preserved in most cases. This provides confidence in obtaining uniform recession on TPS stagnation models in the $229 \mathrm{~mm}(9 \mathrm{in}$.) nozzle at the $\mathrm{x}=76 \mathrm{~mm}$ ( 3 in.) location downstream of the nozzle exit.

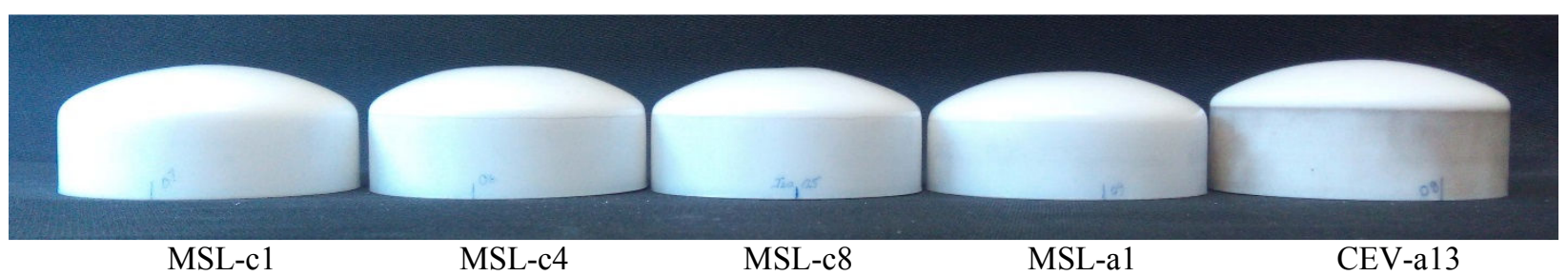

Figure 14. Post-test shapes of $101.6 \mathrm{~mm}(4 \mathrm{in}$.) IsoQ test articles that were tested at $x=76 \mathrm{~mm}(3 \mathrm{in})$.

Varying the $x$-location of the Teflon indicated that testing downstream of $x=76 \mathrm{~mm}$ ( 3 in.) gives significantly different results (see Fig. 15 for tests at MSL c4 condition). While test articles exposed to MSL-c4 at a distance of $\mathrm{x}=25 \mathrm{~mm}, 76 \mathrm{~mm}$ and $229 \mathrm{~mm}$ showed relatively uniform recession, the test articles tested at $\mathrm{x}=127 \mathrm{~mm}$ and $\mathrm{x}=178 \mathrm{~mm}$ did not.

a)
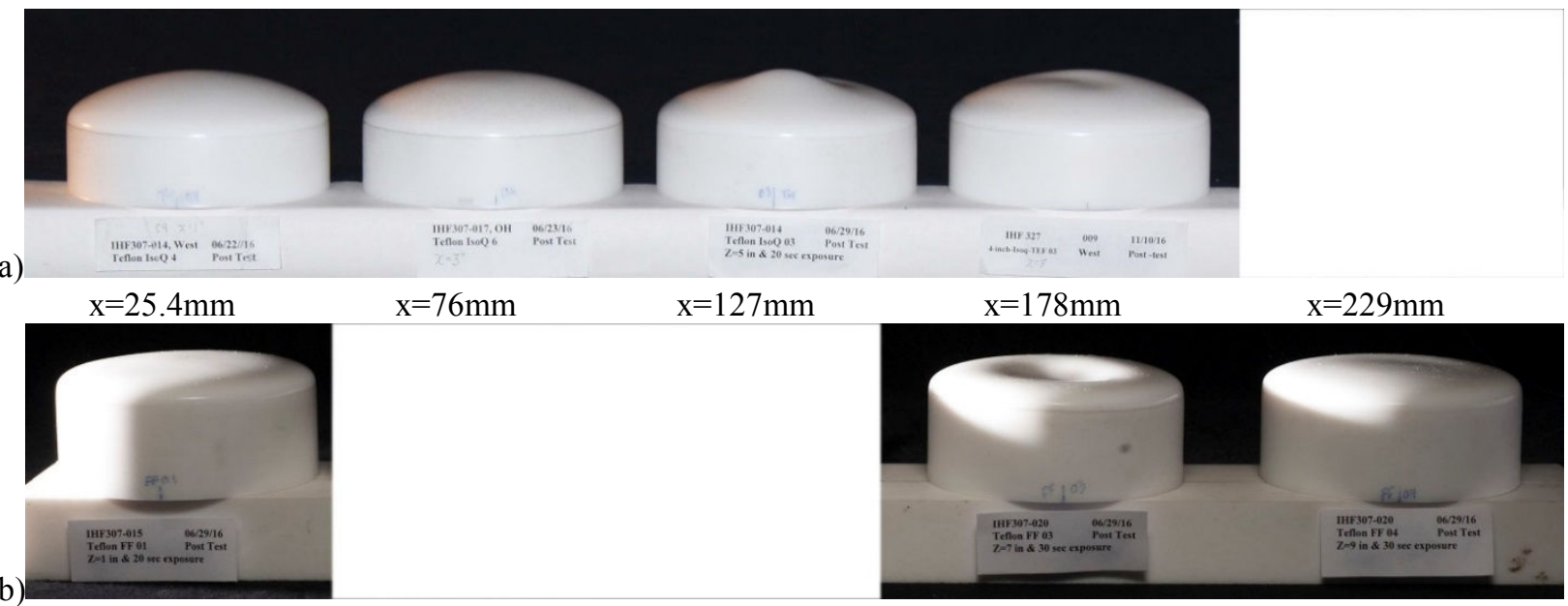

Figure 15. Teflon test articles tested at condition MSL-c4 at various distances from nozzle exit.

a) IsoQ Test Articles and b) Flat Face Test Articles

At $x=127 \mathrm{~mm}$ (see Fig. 15a) the Teflon IsoQ test article showed less recession in the middle of the sample relative to the rest of the sample, indicating a local minimum in heating in the middle of the sample. Conversely, the Teflon IsoQ tested at $\mathrm{x}=178 \mathrm{~mm}$ looks a little flatter (dimple in middle) than its original IsoQ shape, indicating that the heating may be a little higher in the middle (relative to the rest of the sample). 
At some stations flat face test articles were also tested at MSL-c4 condition (see Fig. 15b). At the $\mathrm{x}=178 \mathrm{~mm}$ station the recession of the flat face test article was even more non-uniform than the corresponding IsoQ test article. In this case the recession in the middle of the test article was relatively high (producing a dimple), indicating that heating may have been higher in the middle than at the outer rim of the test article. The non-uniform behavior is attributed to the existence of waves in the free stream generated by the nozzle walls near the throat.

\section{B. 229 mm Nozzle Characterization using Probe Sweeps}

To investigate the reason for the non-uniform recession seen on Teflon we looked at the radial sweeps of calorimeter probes. Noticeably, there is a local minimum in stagnation pressure near the centerline of the jet for the upstream locations, $x=25 \mathrm{~mm}$ and $76 \mathrm{~mm}$. Conversely there is a local maximum in stagnation pressure at the downstream locations, $x=178 \mathrm{~mm}$ and $229 \mathrm{~mm}$ (see Fig. 16).

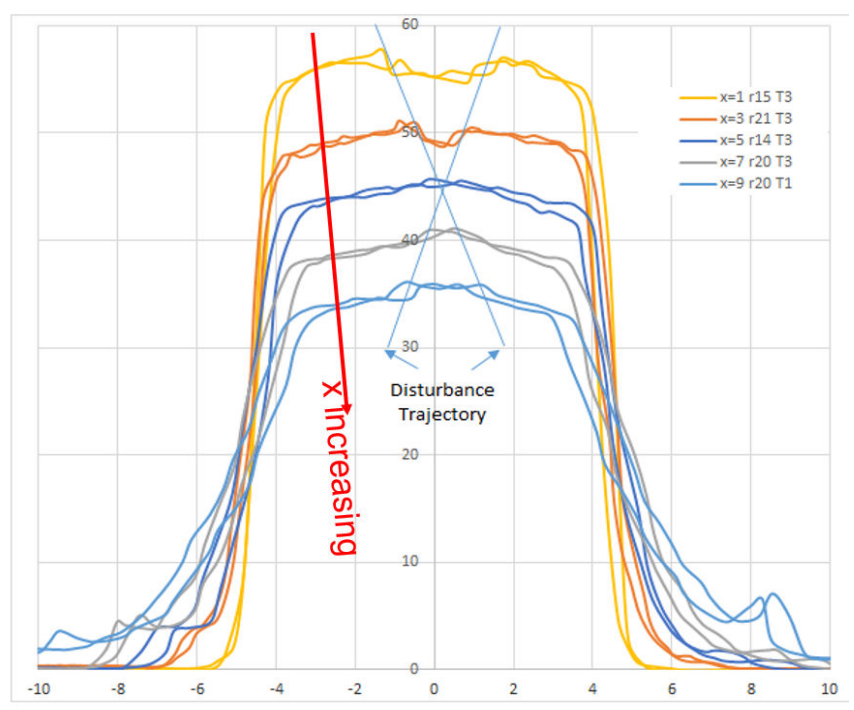

Figure 16. Radial distributions of stagnation pressure at MSL-c4 for various distances from nozzle exit.

The width of the pressure disturbance seems to narrow with distance from the nozzle exit between $x=25 \mathrm{~mm}$ and $x=127 \mathrm{~mm}$, followed by an increase in width of a local maximum from $x=178 \mathrm{~mm}$ to $x=229 \mathrm{~mm}$. The half-width of the local minimum/maximum in pressure is plotted as a function of distance along the nozzle (see Fig. 17).

Interestingly the locus of points appear to lie in a line that passes through the joint between the $152 \mathrm{~mm}$ Nozzle throat section and neighboring $229 \mathrm{~mm}$ nozzle segment. Note that the two segments are very carefully matched with nearly non-existent steps and gaps, consequently we did not expect a flow disturbance from the joint region.

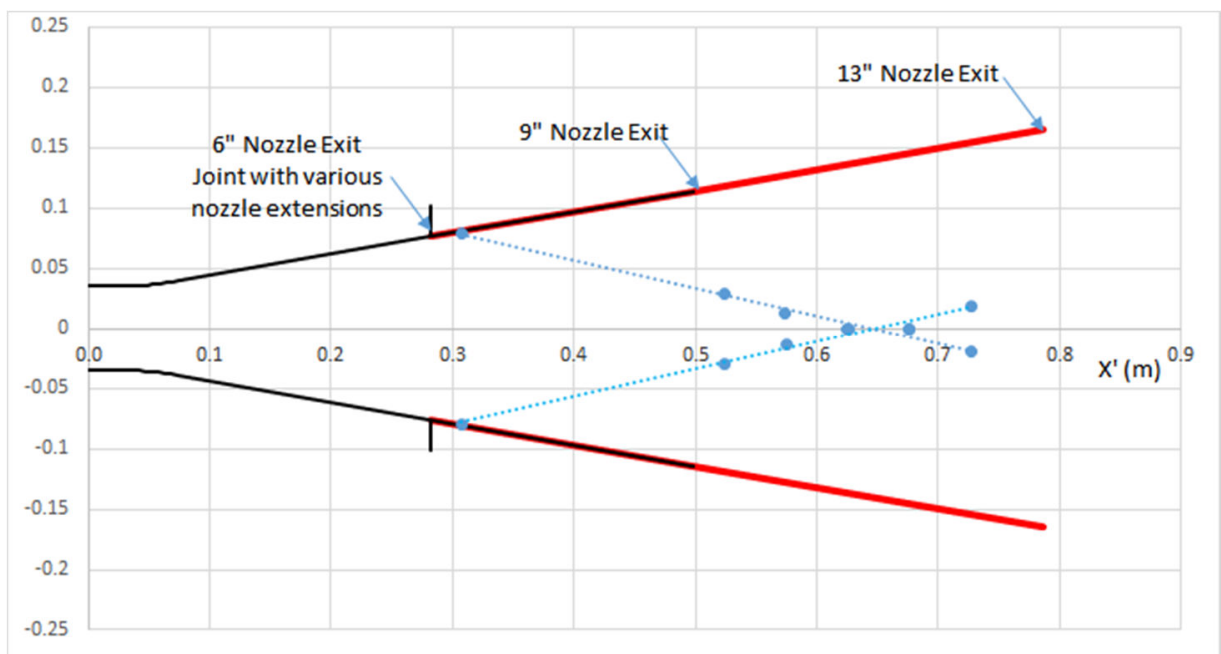

Figure 17. Location of pressure disturbance as a function of distances along the nozzle (dimensions in meters). 


\section{CFD Simulation of Nozzle Throat Waves}

According to Prabhu et.al. [1] CFD predictions of the IHF nozzle flow (without steps or gaps) show that a wave will be spawned from the nozzle throat section and travel across the nozzle centerline to the opposing side of the nozzle where it will impact the nozzle wall at a location downstream of the joint (between nozzle segments). This wave is predicted (by Prabhu et.al. using constant $\gamma=1.4$ ) to reflect off the nozzle wall and travel back towards the centerline of the channel, where it intersects with the nozzle centerline somewhere in the neighborhood of $X^{\prime}=0.8 \mathrm{~m}$, which is not too far from where the waves were seen experimentally.

Figure 18 shows a recent CFD simulation of the $330 \mathrm{~mm}$ diam. nozzle (top half) and $229 \mathrm{~mm}$ diam. nozzle (bottom half) configurations using conditions associated with MSL-c4. Note, both nozzles produce the same flow up to the end of the $229 \mathrm{~mm}$ nozzle. The waves seen in the simulations originate from the abrupt change in curvature of the nozzle shape as it transitions from a circular arc (radius $302 \mathrm{~mm}$ ) to a straight conically diverging $\left(10^{\circ}\right)$ section (infinite radius of curvature) at $X^{\prime}=0.052 \mathrm{~m}$. An abrupt change in curvature is well known to cause pressure waves. Note that the red lines shown on Fig. 18 are characteristic lines associated with waves emanating from the abrupt discontinuity in curvature of the nozzle throat section. According to the CFD these waves travel from the wall to the centerline of the nozzle where they intersect and produce a plateau in Mach number, temperature and stagnation pressure. These conical waves pass through the centerline and impinge on the opposing wall of the nozzle at a location that is upstream of the joint (between adjacent segments of the nozzle). The waves reflect off the nozzle wall and travel back towards the centerline, where a more subtle plateau in Mach\#, temperature and pressure exists at $X^{\prime}=0.48 \mathrm{~m}$. The intersection point of the waves is further upstream than that predicted by Prabhu et.al. [1], we surmise that the difference is due to real gas effects modeled in the present simulation and absent from Prabhu's simulation which used $\gamma=$ const $=1.4$.

A grid of 512x256 was required to resolve these reflected waves, however the simulation shown in Fig. 18 uses a grid of $1024 \times 512$. While there is very little difference in the solution between the $512 \times 256$ and $1024 \times 512$ grids, we think it is prudent to use the finer mesh grid (the cost of a $2 \mathrm{D}$ simulation is minimal). It should be noted that there is no guarantee that the $1024 \times 512$ simulation has completely preserved the waves as the waves are oblique to the grid.

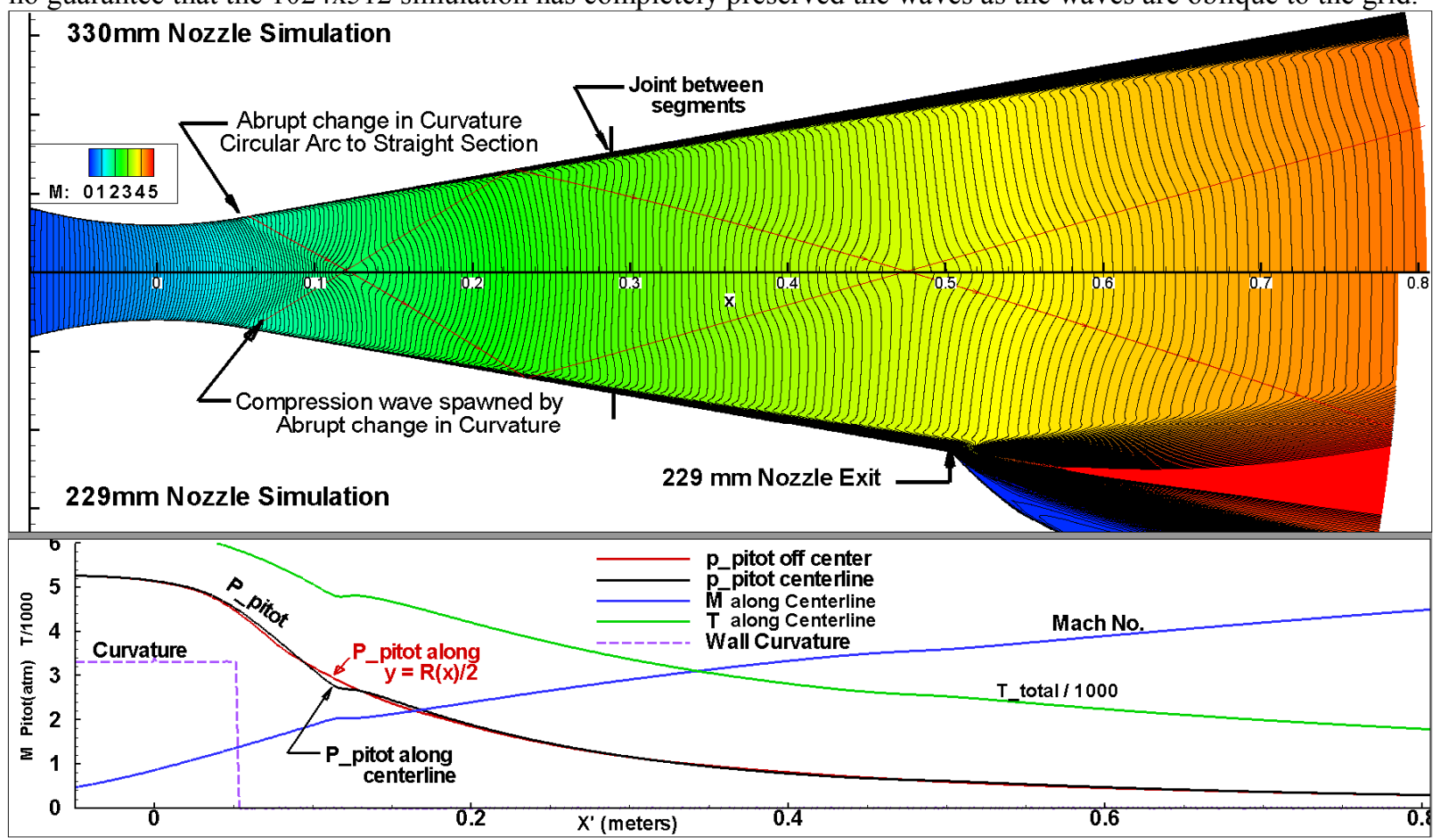

Figure 18. CFD Simulation of IHF 330 mm (top) and IHF 229 mm (bottom) Nozzle under MSL-c4 conditions.

While the pressure plateau looks subtle at the second crossing of the shock waves ( $x=0.48 \mathrm{~m}$ in Fig. 18), it is actually quite noticeable in a close up view of the pressure (see Fig. 19 at $x=0.48 \mathrm{~m}$ ). Note that the black line shows the stagnation pressure along the centerline of the nozzle, and the red line shows the stagnation pressure along a path that is half way between the centerline and the nozzle wall (i.e. $y=R / 2$ ) and is referred to as off-center. There is a local minimum in pressure on the centerline of the flow ahead of the shock intersection point and a local maximum downstream - similar to what was seen in the experiment. 


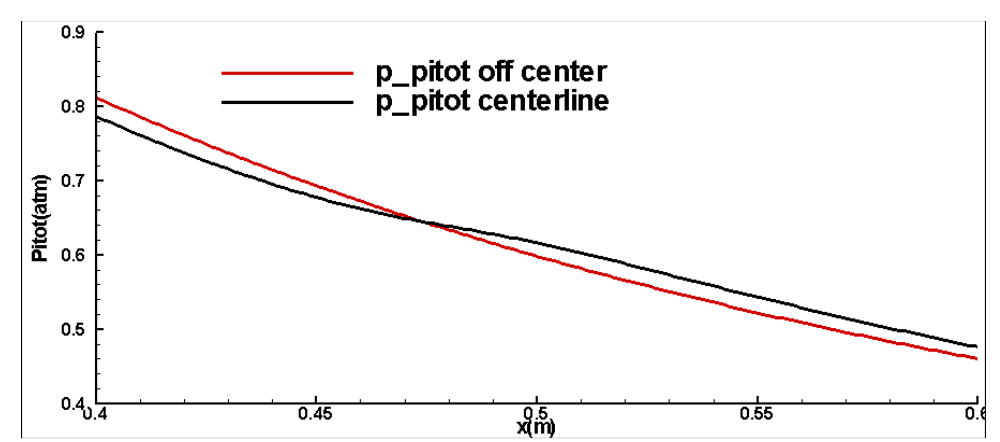

Figure 19. Zoomed in view of Pressure in the vicinity of the waves intersecting.

Note, both nozzles produce the same flow up to the end of the $229 \mathrm{~mm}$ nozzle. Furthermore, the core region of the jet of the $229 \mathrm{~mm}$ nozzle (inside the expansion fan), is the same as in the middle portion of the $330 \mathrm{~mm}$ nozzle. Models that are smaller than the core are not affected by the expansion fan and the flow over the model is the same independent of whether the model is downstream of a $229 \mathrm{~mm}$ nozzle exit or inside of a $330 \mathrm{~mm}$ nozzle. For the purpose of tracking waves through the $229 \mathrm{~mm}$ nozzle and beyond to larger nozzles we are choosing to simulate the $330 \mathrm{~mm}$ nozzle. Simulating the $330 \mathrm{~mm}$ nozzle makes it possible to follow the development of the waves through the $330 \mathrm{~mm}$ nozzle and see the degree to which the waves diverge away from the centerline and out of the path of the test articles downstream of the $330 \mathrm{~mm}$ nozzle. It is worth noting that the waves generated by the abrupt change in curvature of the throat continue to diverge up to $100 \mathrm{~mm}$ away from centerline by the time they exit the $330 \mathrm{~mm}$ nozzle making these waves a relative non-issue for the larger nozzles.

\section{Improved Nozzle Throat Design}

The CFD simulations indicate that at least some waves originate from the nozzle throat section where there is an abrupt discontinuity in nozzle wall curvature. The next step was to see if the waves could be minimized with an improved nozzle throat design - such as modifying the shape of the nozzle throat section so that it is not only continuous and smooth in the first derivative but also the second derivate. To this end a spline shape was devised with the requirement that the second derivative of shape be a smoothly varying function that diminishes to zero as the throat blends into the $10^{\circ}$ conical divergent section. Figure 20 shows one such spline shape used to define the geometry of a potential future nozzle throat section.

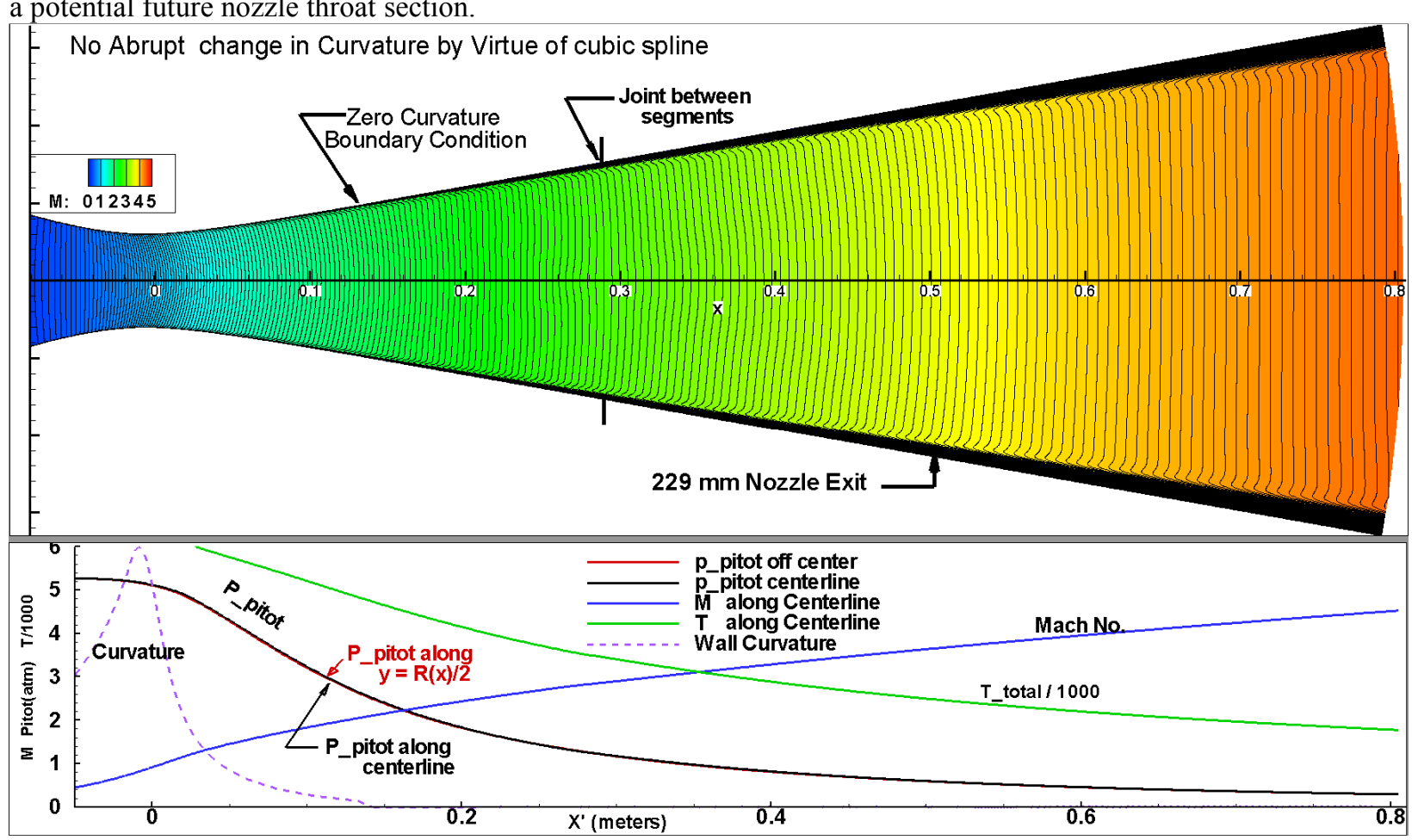

Figure 20. CFD simulation of redesigned nozzle throat.

American Institute of Aeronautics and Astronautics 
The cubic spline version of the nozzle throat geometry appears to have reduced (if not eliminated) the waves emanating from the throat's discontinuity in curvature. CFD predicts that the smoothly varying second derivative of the nozzle wall shape seems to have produced a wave free nozzle flow. Furthermore, the stagnation pressure along the centerline of the nozzle appears to be the same as the stagnation pressure along a trajectory half way between the nozzle centerline and the nozzle wall $(\mathrm{y}=\mathrm{R} / 2)$.

The CFD simulation of the $330 \mathrm{~mm}$ exit diameter nozzle, shows that the new "improved" spline based throat design performs well for the larger nozzle as well as smaller nozzles. While the shape was not optimized with method of characteristics or adjoint methods, the mere elimination of the discontinuity in curvature has dramatically improved the performance of the nozzle. Some minor changes to the design may be necessary to entirely avoid waves in the even larger nozzles $(546 \mathrm{~mm}, 762 \mathrm{~mm}$, and $1041 \mathrm{~mm})$. More work is necessary but it appears that the undesired waves can be reduced significantly by proper nozzle throat contour design.

\section{E. Nozzle Joint Waves}

Discontinuity in curvature may not be the only source of waves. The joint between the throat section and the adjacent nozzle extension section could also be producing waves. To investigate the effect of waves emanating from the joint region of the nozzle, we investigated a hypothetical case in which the tolerances on the $229 \mathrm{~mm}$ nozzle extension conspired to give us a nozzle extension wall angle that is $9.97^{\circ}$ rather than the desired $10^{\circ}$ (a mere $0.03^{\circ}$ mismatch in angle). The corresponding CFD simulation with current nozzle throat (circular arc) and joint angle mismatch of $0.03^{\circ}$ is shown in Fig 21 .

This simulation shows a second set of waves emanating from the nozzle joint at $X^{\prime}=0.29 \mathrm{~m}$, where there is a discontinuity in slope (indicated by a spike in curvature in Fig. 21b). These compression waves intersect (come to a focus) at $X^{\prime} \sim 0.61$ meters which is $\sim 110 \mathrm{~mm}$ downstream of where the $229 \mathrm{~mm}$ nozzle ends. This is downstream of the set of waves emanating from the discontinuity in nozzle throat curvature. We expect a similar set of waves would be produced by a step discontinuity at the joint.

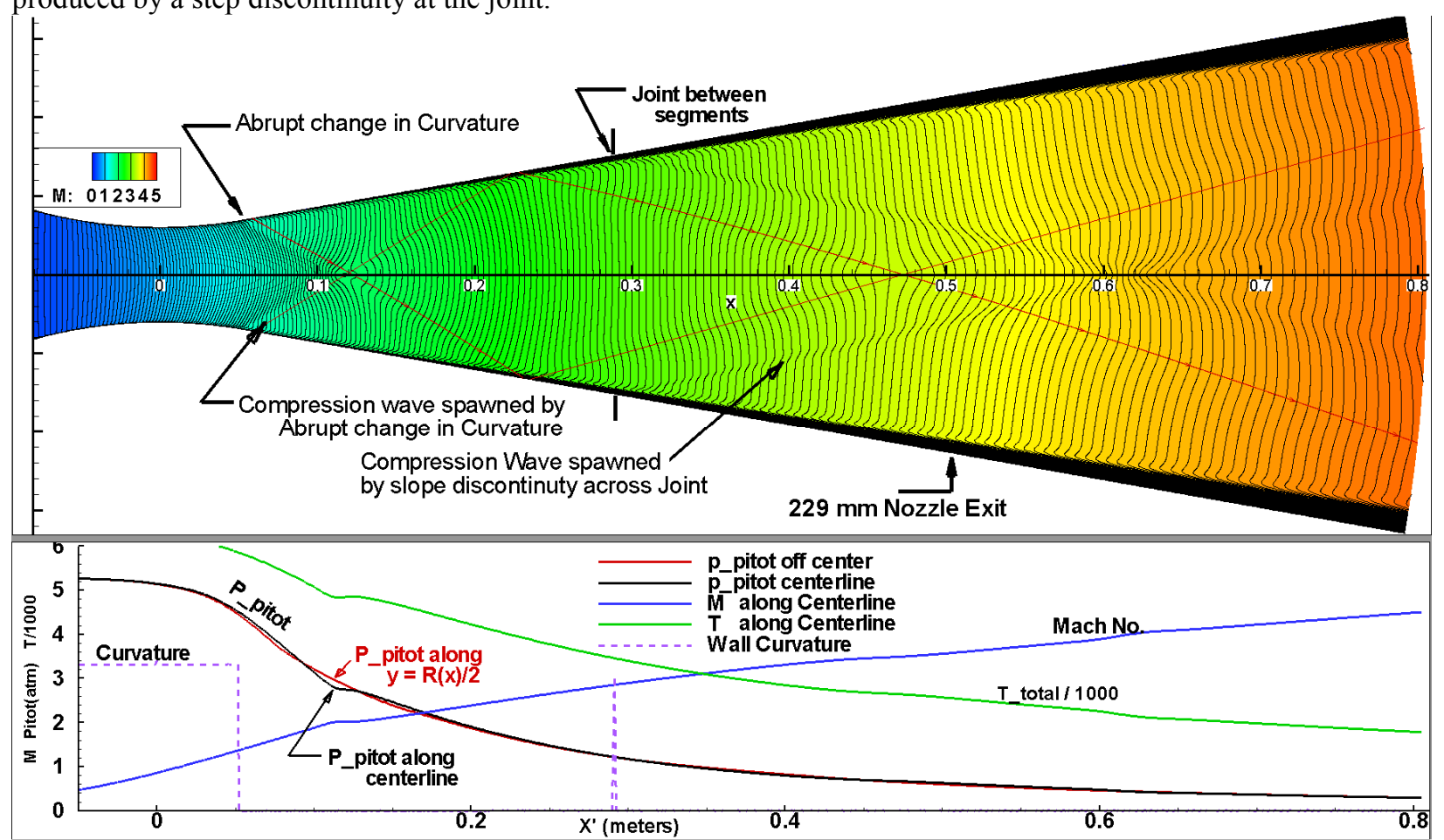

Figure 21. CFD simulation of IHF $330 \mathrm{~mm}$ Nozzle with discontinuity in slope of the wall at the joint.

The effect of this nozzle flow on the heating to the $101.6 \mathrm{~mm}$ diam. IsoQ stagnation probe is simulated and shown in Fig 22. There is a noticeable local minimum in heating at the centerline of the $101.6 \mathrm{~mm}$ IsoQ stagnation model for the case where the model is located at the $\mathrm{x}=127 \mathrm{~mm}$ station. Recall that the Teflon recession showed an anomalous minimum in recession (maximum in post-test shape) at the center of the Teflon test article. The waves emanating from a discontinuity in slope at the joint seem to offer a plausible explanation for the Teflon behavior. 


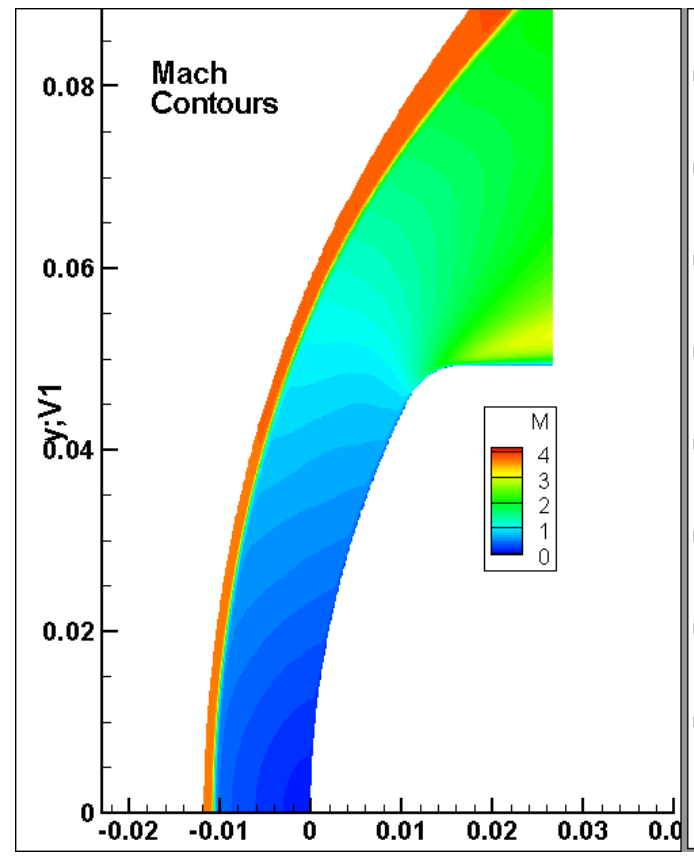

a) Mach Contours at $x=25 \mathrm{~mm}$

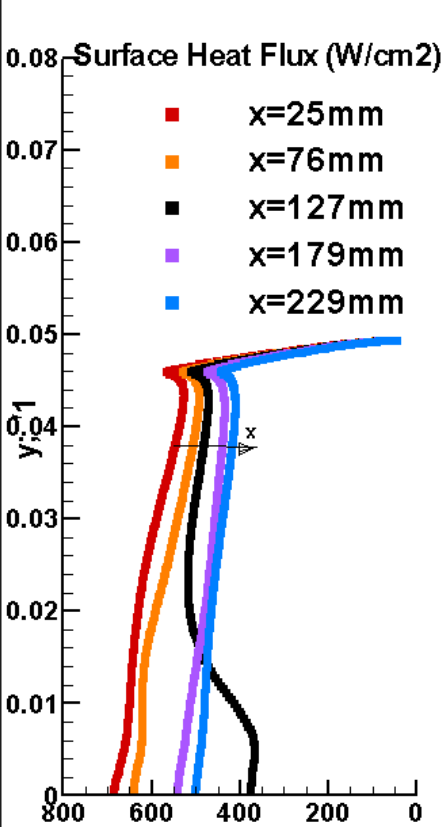

b) Heat Flux

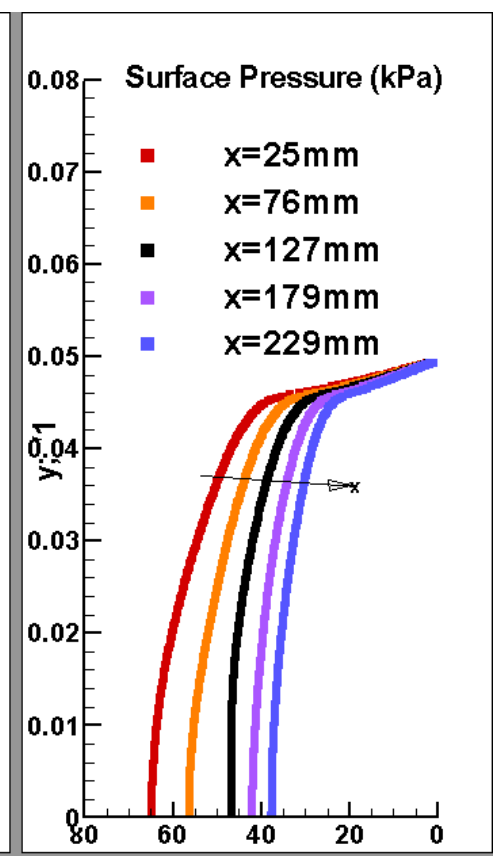

c) Pressure

Figure 22. CFD simulation of a $101.6 \mathrm{~mm}$ IsoQ stagnation model in IHF $330 \mathrm{~mm}$ Nozzle with waves.

Another set of CFD simulations was performed on the Flat Face shape (see Fig. 23). Interestingly, there is a local maximum in heating at the centerline of the test article for Flat Face test articles placed at the $\mathrm{x}=179 \mathrm{~mm}$ stations (purple line). Recall that there was a local maximum in recession (dimple) seen in the Flat Face Teflon model that was tested at the $\mathrm{x}=179 \mathrm{~mm}$ station. Again waves emanating from the joint are offering a plausible explanation for the Teflon recession behavior.

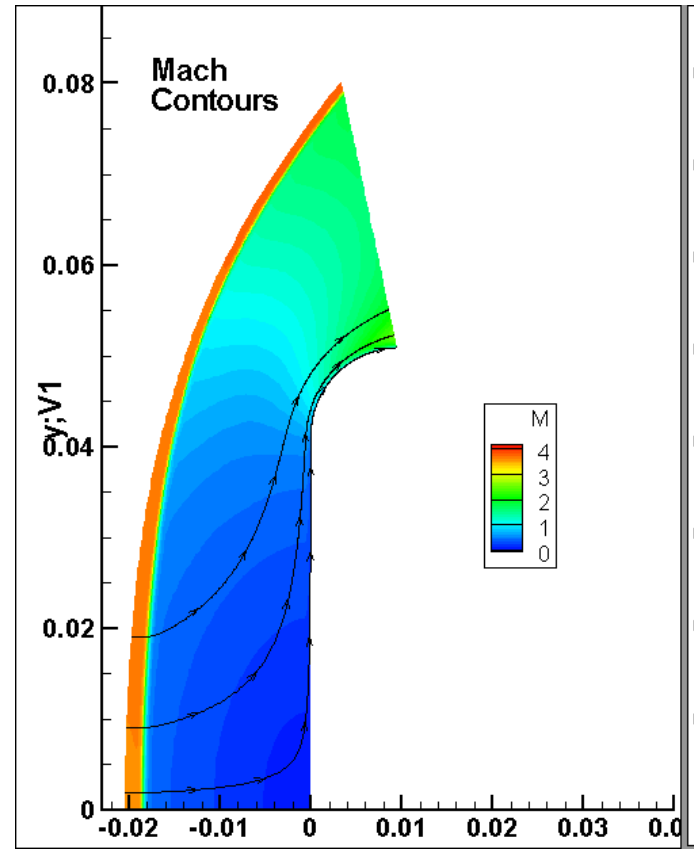

a) Mach Contours at $x=25 \mathrm{~mm}$

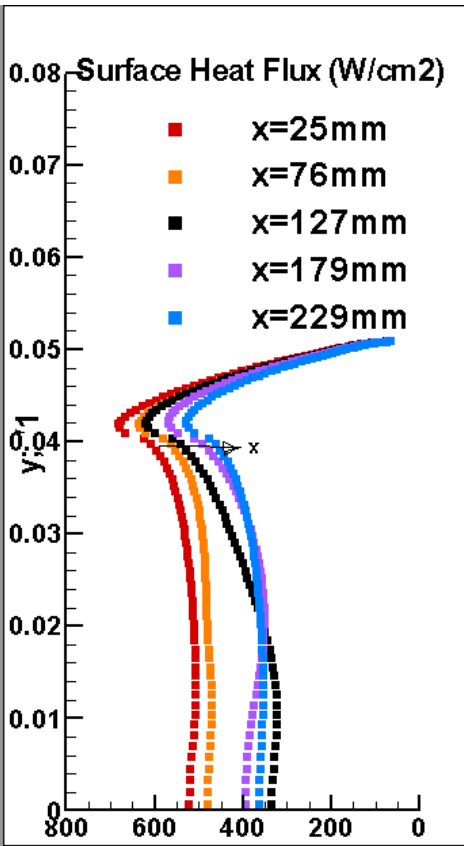

b) Heat Flux

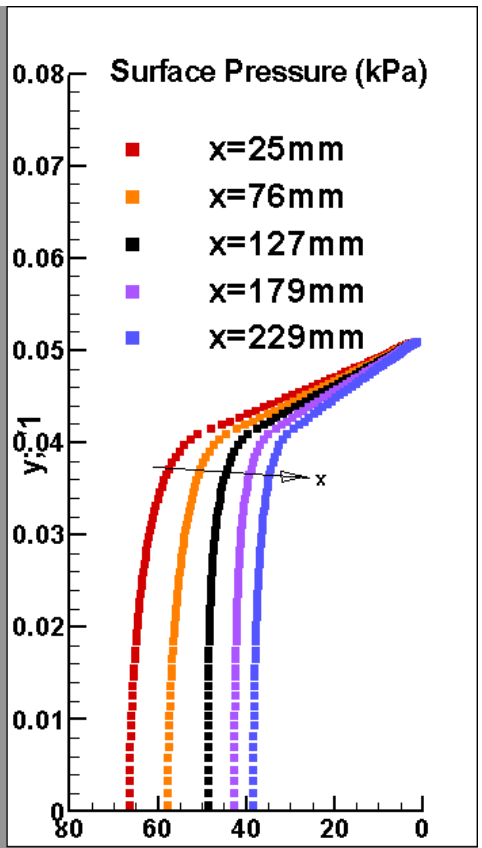

c) Pressure

Figure 23. CFD simulation of $101.6 \mathrm{~mm}$ Flat Face stagnation model in IHF 330 $\mathrm{mm}$ Nozzle with waves.

Another set of CFD simulations was performed on the $101.6 \mathrm{~mm}$ diam. hemispherical calorimeter (see Fig 24). Simulations indicate that that waves from the joint are interacting most severely when the model is at the $\mathrm{x}=127 \mathrm{~mm}$ 
location. The heating distribution bears some resemblance to the heating distribution seen on the $101.6 \mathrm{~mm}$ Isoq shape at the $x=127 \mathrm{~mm}$ station. It would appear that the waves interact with the smaller radius hemispherical probe less severely than they do with larger radius of curvature IsoQ and Flat Face shapes.

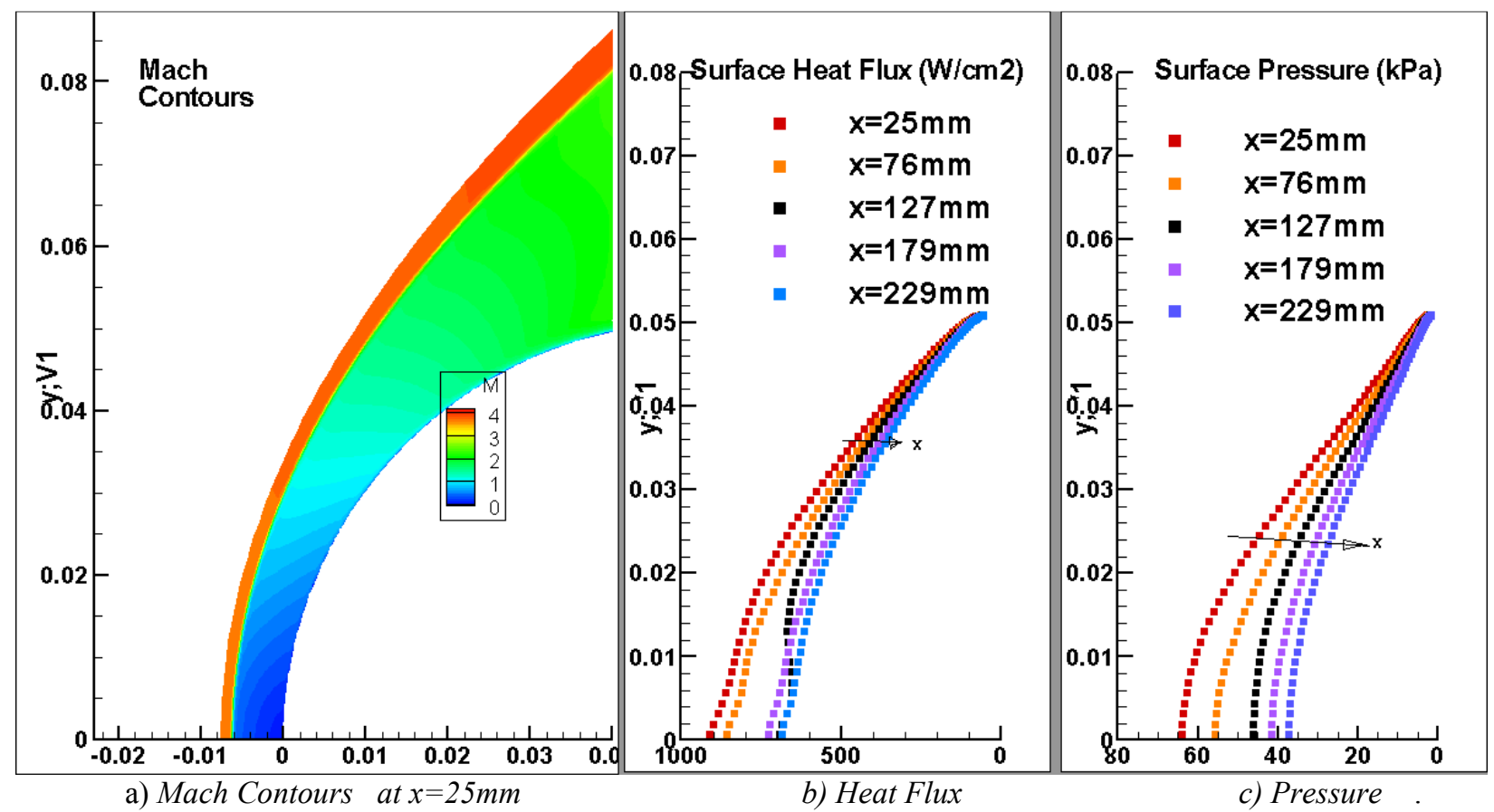

Figure 24. CFD simulation of $101.6 \mathrm{~mm}$ diam. Flat Face stagnation model in IHF 330 $\mathrm{mm}$ Nozzle with waves.

\section{Discussion}

It is interesting that the waves interact with the test articles differently between the IsoQ shape and the Flat Face shapes. In the case of the IsoQ (at $x=127 \mathrm{~mm}$ ) the waves create a local minimum in heating that otherwise wouldn't be there in a flow with a uniform free stream, while the waves produce a local maximum in heating on the center of the Flat Face (at $x=178 \mathrm{~mm}$ ) that otherwise would not have been there in the case of a uniform free stream. This behavior makes it difficult to use correlations like Fay-Riddell [11] to estimate the free stream enthalpy from heating at a stagnation point.

It has been our experience that the majority of our flow quality issues come from the smaller nozzles, whether it be the IHF or AHF. Waves in these smaller nozzle may be the source of the issue where heating is not scaling with the square root of the nose radius as Zoby [12] would suggest.

Note that the nozzle is axisymmetric and the waves follow a conical trajectory which intersects at a point, making the combined effect of all waves coming together more severe than if the nozzle were a 2D planar nozzle.

The large nozzles likely have waves also but the waves are not coming to a focus at locations where the test articles are positioned. Furthermore the flow inside the larger nozzles is at higher Mach numbers making the waves follow a trajectory that is more parallel to the free stream making them less likely to intersect (come to a focus) in the region of test articles.

One could try to analyze the anomalous behavior associated with waves interacting with various models, but it is preferable to reduce the strength or eliminate the source of the waves. It might be worth investigating the use of a spline shape to define the inner mold line of future nozzle throat sections to eliminate the waves emanating from the nozzle throat discontinuity in curvature (i.e. develop a smooth and continuous $2^{\text {nd }}$ derivative of nozzle contour). Secondly it is worth considering the fabrication of future nozzles with no joints, or perhaps pinning nozzle segments together and machine all nozzle segments while they are mated together.

\section{Conclusions}

A test series was conducted on a newly built nozzle extension with $229 \mathrm{~mm}$ (9 in.) exit diameter. Teflon recession data was obtained on $101.6 \mathrm{~mm}$ (4 in.) diameter Flat Face and IsoQ models, revealing good flow quality when models were placed within $76 \mathrm{~mm}(3 \mathrm{in}$.) of the nozzle exit. However, Teflon models placed downstream of the $\mathrm{x}=76 \mathrm{~mm}$ 
station showed non-uniform recession. IsoQ models placed at $\mathrm{x}=127 \mathrm{~mm}(5 \mathrm{in}$.) produced a local minimum in recession at the center of the model, while Flat Face models placed at $x=178 \mathrm{~mm}$ ( 7 in.) produced a local maximum in recession at the center of the Teflon test article.

Pressure probe surveys of the free jet revealed that there is a standing conical wave in the nozzle that converges to a point in the neighborhood of $x=127 \mathrm{~mm}(5 \mathrm{in}$.). Upstream of $\mathrm{x}=127 \mathrm{~mm}$ the stagnation pressure forms a local minimum in pressure at the centerline of the jet, while downstream of $x=127 \mathrm{~mm}$ the stagnation pressure forms a local maximum in pressure at the centerline of the jet.

According to CFD analysis of the nozzle throat, waves are produced at the abrupt change in curvature at the location where the nozzle transitions from a circular arc to a linear conical shape. This discontinuity in the second derivative of the shape appears to be causing one set of standing waves. CFD analysis showed that a redesigned nozzle throat (with smoothly varying curvature that diminishes to zero) is capable of expanding the flow without producing waves. This entailed changing the inner mold line contour from the old circular arc design to a new spline design resulting in a shape change of less than $1.25 \mathrm{~mm}(0.050 \mathrm{in}$.) everywhere.

A second set of waves may be generated by the nozzle at the joint between the throat segment and nozzle extension segment (possibly due to discontinuities in slope, steps or gaps). CFD simulations were performed on a hypothetical geometry in which the nozzle wall angle jumps from $10^{\circ}$ to $9.97^{\circ}$ across the joint. The CFD indicates that this minor slope discontinuity was capable of generating waves that follow a conical trajectory toward a point that is $\sim 110 \mathrm{~mm}$ downstream of the nozzle exit plane. This set of waves produces an interaction with the test articles (IsoQ, Flat Face and Hemispherical shapes) that results in a deviation in heating from that of a test article in a uniform free stream and this deviation is most pronounced at the $\mathrm{x}=127 \mathrm{~mm}$ and $179 \mathrm{~mm}$ test positions. The CFD predicted heating trends on these test articles indicate that waves emanating from the joint could be responsible for the non-uniform recession seen on the Teflon test articles.

The results of the simulations indicate that the waves spawned by the nozzle throat section and the joint are less of a problem for the existing $152 \mathrm{~mm}(6 \mathrm{in}$.) and $330 \mathrm{~mm}$ (13 in.) nozzles because the intersection of the conical wave is far away from the location where models are commonly placed in those two nozzles.

\section{Acknowledgments}

We would like to thank George Raiche, Scott Eddlemon, Jeremy Vander Kam, Pete Zell, and the crew of the Arc Jet complex. We are also grateful for the reviews and instructive conversations with John Balboni, Megan MacDonald, David Hash and Dean Kontinos. This work was partially funded under the NASA Strategic Capabilities Assets Program (SCAP) along with the LEAF-LITE and MCVP programs.

\section{References}

[1] D. Prabhu, D. A. Saunders, T. Oishi, K. Skokova, J. Santos, J. Fu, I. Terrazas-Salinas, J. E. J. Carballo and D. M. Driver, "CFD Analysis Framework for Arc-Heated Flowfields, I: Stagnation Testing in Arc-jets at NASA ARC," in AIAA 20094080, San Antonio, TX, 2009.

[2] D. M. Smith, H. Moody, C. Wanstall and I. Terrazas-Salinas, "The Design and Use of Calorimeters For Characteriization of High-Enthalpy Flows in Arc-Heated Test Facilities," in AIAA 2002-5236, Orleans, France, 2002.

[3] W. Winovich and W. Carlson, "The 60 MW Shuttle Interaction Heating Facility," in 25th International Instrumentation Symposium, Anaheim, CA, 2979.

[4] D. M. Driver, ,. J. E. J. Carballo, R. Beck, C. Tang, J. Santos, A. Cassell, K. Skokova, H. Hwang, E. Slimko, W. Willcockson and J. Songer, "Arc Jet Testing in a shear Environment for Mars Science Laboratory Theral Protection System," Journal of Spacecraft and Rockets, vol. 51, no. 4, pp. 1151-1166, 2014.

[5] I. Terrazas-Salinas, J. E. J. Carballo, D. M. Driver and J. A. Balboni, "Comparison of Heat Transfer Measurement Devices in Arc Jet Flows with Shear," in AIAA 2010-5053, Chicago, IL, 2010.

[6] C. T. Kidd, "High Heat-Flux Measurements and Experimental Calibrations/Characterization," NASA CP 3161 pp 31-50, 1992.

[7] Medtherm Corp, "Coaxial Surface Thermocouple Probe, Bulletin 500," Medtherm Corp., , PO Box 412 Huntsville AL 35804 , $\mathrm{Ph}$ 256-837-2000.

[8] "ASTM Standard E598-96; Standard Test Method for Measuring Heat-Transfer Rates from High-Energy Environments Using a Transient Null-Point Calorimeter," ASTM International, West Conshohocken, PA, http://www.astm.org, 2002.

[9] "ASTM Standard E457-96; Standard Test Method for Measuring Heat-Transfer Rate Using a Thermal Capacitance (Slug) Calorimeter," ASTM International, West Conshohocken, PA, http://www.astm.org, 2002, 2002.

[10] "ASTM Standard E457-96; Standard Test Method for Measuring Heat-Transfer Rate Using a Thermal Capacitance (Slug) Calorimeter," ASTM International, http://www.astm.org, West Conshohocken, PA, 2002. 
[11] J. A. Fay and F. R. Riddell, "Theory of Stagnation Point Heat Transfer in Dissociated Air," Journal of the Aeronautical Sciences, vol. 25, no. 2, pp. 73-85, 1958.

[12] E. V. Zoby, "Emprical Stagnation-Point Heat-Transfer Relation in Several Gas Mixtures at High Enthalpy Levels," NASA TN-D4799, 1968. 